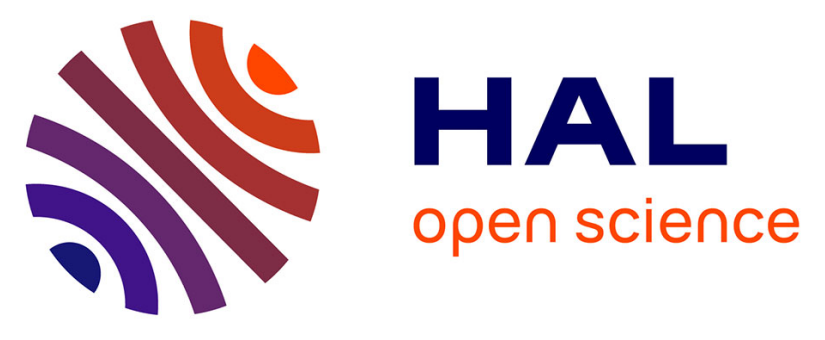

\title{
Impact of Solution Chemistry on Growth and Structural Features of Mo-substituted Spinel Iron Oxides
}

Chérazade Haouari, Alexander G Squires, Romain Berthelot, Lorenzo Stievano, Moulay Tahar Sougrati, Benjamin J Morgan, Oleg I Lebedev, Antonella Iadecola, Olaf J Borkiewicz, Damien Dambournet

\section{To cite this version:}

Chérazade Haouari, Alexander G Squires, Romain Berthelot, Lorenzo Stievano, Moulay Tahar Sougrati, et al.. Impact of Solution Chemistry on Growth and Structural Features of Mo-substituted Spinel Iron Oxides. Inorganic Chemistry, 2021, 60 (10), pp.7217-7227. 10.1021/acs.inorgchem.1c00278 . hal-03222581

\section{HAL Id: hal-03222581 \\ https: / hal.sorbonne-universite.fr/hal-03222581}

Submitted on 10 May 2021

HAL is a multi-disciplinary open access archive for the deposit and dissemination of scientific research documents, whether they are published or not. The documents may come from teaching and research institutions in France or abroad, or from public or private research centers.
L'archive ouverte pluridisciplinaire HAL, est destinée au dépôt et à la diffusion de documents scientifiques de niveau recherche, publiés ou non, émanant des établissements d'enseignement et de recherche français ou étrangers, des laboratoires publics ou privés. 


\section{The Impact of Solution Chemistry on Growth and}

\section{Structural Features of Mo-substituted Spinel Iron}

\section{Oxides}

Chérazade Haouari ${ }^{\mathrm{a}, \mathrm{b}, \mathrm{c}}$, Alexander G. Squires ${ }^{\mathrm{d}, \mathrm{e}}$, Romain Berthelot ${ }^{\mathrm{a}, \mathrm{c}^{*}}$, Lorenzo Stievano ${ }^{\mathrm{a}, \mathrm{c}^{*}}$, Moulay Tahar Sougrati ${ }^{\mathrm{a}, \mathrm{c}}$, Benjamin J. Morgan ${ }^{\mathrm{d}, \mathrm{e}}$, Oleg I.Lebedev ${ }^{\mathrm{f}}$, Antonella Iadecola ${ }^{\mathrm{c}}$, Olaf J. Borkiewicz $^{\mathrm{g}}$, Damien Dambournet ${ }^{\mathrm{b}, \mathrm{c}^{*}}$

${ }^{a}$ ICGM, Univ. Montpellier, ENSCM, CNRS, Montpellier, France

${ }^{\mathrm{b}}$ Sorbonne Université, CNRS, Physico-chimie des électrolytes et nano-systèmes interfaciaux, PHENIX, F-75005 Paris, France

${ }^{\mathrm{c}}$ Réseau sur le Stockage Electrochimique de l'Energie (RS2E), CNRS, Amiens, France

${ }^{\mathrm{d}}$ Department of Chemistry, University of Bath, BA2 7AY Bath, United Kingdom

${ }^{\mathrm{e}}$ The Faraday Institution, Quad One, Harwell Science and Innovation Campus, Didcot OX11 ORA, U.K

${ }^{\mathrm{f}}$ Laboratoire CRISMAT, ENSICAEN, Université de Caen, CNRS, F-14050, Caen, France

${ }^{\mathrm{g}}$ X-ray Science Division, Advanced Photon Source, Argonne National Laboratory, 9700 South Cass Avenue, Argonne, Illinois 60439, United States 


\section{AUTHOR INFORMATION}

\section{Corresponding Authors}

* romain.berthelot@umontpellier.fr, lorenzo.stievano@umontpellier.fr, damien.dambournet@ sorbonne-universite.fr,

ABSTRACT. The effect of crystallizing solution chemistry on the chemistry of subsequently asgrown materials was investigated for Mo-substituted iron oxides prepared by thermally activated co-precipitation. In the presence of Mo ions, we find that varying the oxidation state of the iron precursor from $\mathrm{Fe}(\mathrm{II})$ to $\mathrm{Fe}(\mathrm{III})$ causes a progressive loss of atomic long-range order with the stabilization of 2-4 nm particles for the sample prepared with Fe(III). The oxidation state of the Fe precursor also affects the distribution of $\mathrm{Fe}$ and Mo cations within the spinel structure. Increasing the Fe precursor oxidation state gives decreased Fe-ion occupation and increased Mo-ion occupation of tetrahedral sites, as revealed by EXAFS. The stabilization of Mo within tetrahedral sites appears to be unexpected considering the octahedral preferred coordination number of Mo(VI). The analysis of the atomic structure of the sample prepared with Fe(III) indicates a local ordering of vacancies and that the occupation of tetrahedral sites by Mo induce a contraction of the inter-atomic distances within the polyhedra as compared to Fe atoms. Moreover, the occupancy of Mo into thermodynamic site preference of a Mo dopant in $\mathrm{Fe}_{2} \mathrm{O}_{3}$ assessed by DFT-calculations, points to a stronger preference for Mo substitution at octahedral sites. Hence, we suggest that the synthetized compound is thermodynamically metastable, i.e., kinetically trapped. Such a state is suggested to be a consequence of the tetrahedral site occupation by Mo ions. The population of these sites, known to be reactive sites enabling particles growth, is concomitant with the stabilization of very small particles. We confirmed our hypothesis by using a blank experiment without Mo ions, further supporting the impact of tetrahedral Mo ions on the growth of iron oxide 
nanoparticles. Our findings provide new insight into the relationships between the Fe-chemistry of the crystallizing solution and the structural features of as-grown Mo-substituted Fe-oxide materials.

KEYWORDS. Spinel, cationic vacancies, nanoparticles growth, disordered structure. 


\section{INTRODUCTION}

The spinel structure is widely observed in solid-state chemistry. It can be synthesized with a large number of compositions and provides an adaptable framework for tuning material properties and structural features. ${ }^{1,2}$ A good example of this compositional and structural versatility is provided by iron-oxide-based spinels, which can be synthesized with variable numbers of cationic vacancies to form solid solutions with general formula $\mathrm{Fe}_{3-x} \square_{x} \mathrm{O}_{4}$, where $\square$ represents a vacancy and $x$ ranges from 0 to 0.33 . The end members for this compositional range are stoichiometric magnetite $\mathrm{Fe}_{3} \mathrm{O}_{4}$ - which contains both $\mathrm{Fe}(\mathrm{II})$ and $\mathrm{Fe}(\mathrm{III})$ iron oxidation states-and fully oxidized maghemite $\gamma-\mathrm{Fe}_{2} \mathrm{O}_{3}$-which contains only $\mathrm{Fe}(\mathrm{III})$. In cation-deficient spinels, the cation vacancies can adopt different arrangements within the host structure, and the precise cation-vacancy configuration dictates the overall crystallographic symmetry. In $\gamma-\mathrm{Fe}_{2} \mathrm{O}_{3}$, for example, the cation vacancies can adopt a number of ordered arrangements, ${ }^{3-5}$ or can be randomly arranged, giving cubic crystallographic symmetry. ${ }^{6}$

The nucleation and growth of iron oxide crystals from solution is understood to progress via the aggregation of pre-nucleation clusters, ${ }^{7-9,10,11}$ as described by the non-classical theory of nucleation. ${ }^{12-14}$ The details of this nucleation and growth process are sensitive to a number of factors ${ }^{15}$ ( $\mathrm{pH}$, temperature, precursors). For example, by adjusting the chemistry of the crystallizing solution, by using precursors that contain metals in specific oxidation states, it is possible to direct the growth of specific crystal phases by modifying the linkages within the prenucleation clusters and hence affecting cluster aggregation. ${ }^{8} \mathrm{~A}$ second factor is the role of point defects, such as cationic vacancies, which can act as reactive sites during crystal growth, thereby

providing a second potential mechanism for directing crystal nucleation and growth. ${ }^{16,17}$ The degree to which point defects form during crystallization, however, depends on the chemistry of 
the crystallizing solution and the growth conditions, often making it challenging to deconvolve the contribution of each factor in directing the growth of specific crystal structures.

One practical approach towards resolving these relationships between solution chemistry, the formation of cation vacancies during crystal growth, and the crystal structure of the as-grown product, is to study systems in which there is a direct link between the chemistry of the crystallizing solution and the chemistry of the as-grown materials. ${ }^{17}$ On the one hand, varying the iron precursor oxidation state is known to have a critical role in the formation of iron oxide nanoparticles ${ }^{18}$. On the other hand, cation vacancy numbers can be increased by including supervalent dopant such as Mo ions in the crystallizing solution, which promote vacancy formation through charge compensation. ${ }^{19-26}$ The combined effect of varying the oxidation state of iron precursor, and increasing the cationic vacancies number by means of the presence of the supervalent (Mo) ions in the crystallization solution has never been examined so far. This is of particular interest as various highly cation-deficient metal oxides showed promising electrochemical properties for use in energy storage. ${ }^{27,28,28}$

To investigate the above-mentioned combined effect, we have performed a series of thermallyactivated coprecipitation syntheses, adapted from Hahn's protocol ${ }^{21}$, where the crystallization solution included Mo ions and different iron oxidation state precursors. To characterize the structure of the resulting oxide nanoparticles we applied a range of complementary scattering and spectroscopic techniques including X-ray diffraction (XRD), Pair Distribution Function (PDF) analysis, X-ray absorption spectroscopy (XAS), ${ }^{57} \mathrm{Fe}$ Mössbauer spectroscopy and DFTcalculations. The resulting data indicate that tuning the chemistry of the starting solution, i.e., varying the oxidation state of iron precursor in the presence of Mo ions, affects both the oxidation state of the cations and the product atomic structure. In particular, we hypothesize a link between 
crystal growth and the resulting distribution of cations between tetrahedral and octahedral cation sites within the spinel. We found that the occupancy of $\operatorname{Mo}(\mathrm{VI})$ within tetrahedral sites is concomitant with a decrease of the size particles. The occupancy of Mo(VI) within these sites is unexpected as Mo is predicted on thermodynamic grounds to preferentially occupy octahedral sites. This kinetic preference for tetrahedral-Mo is suggested to block the particles growth further enabling the stabilization of very small particles.

\section{RESULTS AND DISCUSSION}

\section{Synthesis approach: influence of the iron precursor}

Mo-substituted iron oxides were prepared by a thermally activated co-precipitation method. High charge Mo ions were selected to favor the formation of cationic vacancies by a chargecompensating mechanism. In a typical synthesis, the molar ratio Mo/Fe was fixed to 0.19 and the iron oxidation state precursor was varied. The effect of tuning the Fe precursor on the crystallinity of the resulting particles is evident from the collected XRD patterns (Figure 1a). Starting from a pure $\mathrm{Fe}$ (II) precursor gives a well-crystallized phase that can be indexed to the $F d-3 m$ and/or the $P 4332$ space groups. A small peak located around $34.3^{\circ}(2 \theta)$ suggests the presence of minor amounts of a second phase. Starting with an equimolar ratio of $\mathrm{Fe}(\mathrm{II})$ and $\mathrm{Fe}(\mathrm{III})$ gives an XRD pattern with much less structure. Closer analysis of this XRD pattern, however, reveals Bragg peaks that can still be indexed to the spinel structure ( $F d-3 m$ or $P 4_{3} 32$ space groups). In contrast, starting from a pure $\mathrm{Fe}(\mathrm{III})$ precursor gives a product XRD pattern with only diffuse scattering, indicating the absence of long-range order typical of amorphous compounds.

To better understand how the choice of crystallization precursor affects the atomic structure of the

product phase, we applied PDF analysis. ${ }^{29} \mathrm{PDF}$ analysis describes structural correlations across a 
range of length scales, from short- to long-range, making it particularly useful for probing disordered or amorphous or nanoscale materials. ${ }^{30}$ We first consider the short-range features at distances between $1.5 \AA$ and $4.0 \AA$ (Figure 1b). This range includes the $M-\mathrm{O}$ distances $(M=\mathrm{Mo}$, Fe) for octahedral and tetrahedral sites at $\sim 2 \AA$. The next two peaks at $\sim 3 \AA$ and $\sim 3.5 \AA$ correspond to cation-cation distances between adjacent octahedral site-pairs $\left(M_{\mathrm{oct}}-M_{\mathrm{oct}}\right.$ pairs) and between neighboring octahedral-tetrahedral site-pairs $\left(M_{\mathrm{oct}}-M_{\text {tet }}\right.$ pairs $)$, respectively. ${ }^{31}$ Increasing the ratio of $\mathrm{Fe}(\mathrm{III})$ to $\mathrm{Fe}(\mathrm{II})$ in the precursor has two visible effects on this short-range PDF data. First, the $M-\mathrm{O}$ peak to shift to smaller distances, which is consistent with the expected change in average cation oxidation state. Second, these short-range peaks all broaden, indicating a greater variance in interatomic distances that is consistent with the increasing disorder indicated by our XRD data. This increased disorder with increasing Fe(III) content is also apparent in the intermediate-to-longrange PDF data ( $r=4 \AA$ to $50 \AA$ ) (Figure 1c). The extent of the resolvable PDF signal represents the structural coherence length. We observed a progressive decrease of the long-range order with increasing $\mathrm{Fe}(\mathrm{III})$ in the precursor. For the sample prepared with the Fe(II) precursor the PDF data shows clear structure up to $50 \AA$, the dampening of the PDF with increasing inter-atomic distances significantly increases when introducing Fe(III) with coherence length decreasing to about $20 \AA$ for the sample prepared with Fe(III). 

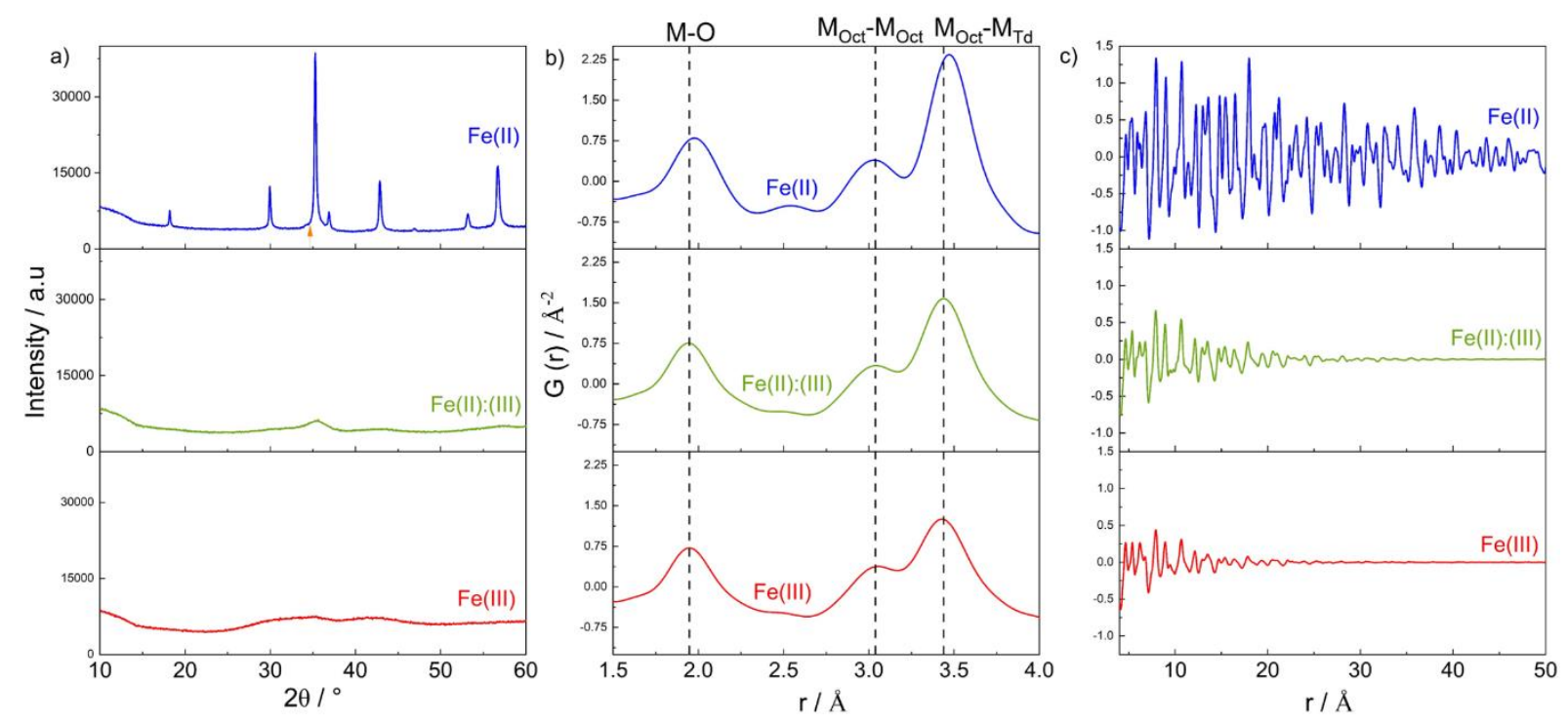

Figure 1. a) X-ray diffraction patterns of the samples prepared by varying the Fe precursors from $\mathrm{Fe}(\mathrm{II})$ (blue), equimolar ratio $\mathrm{Fe}(\mathrm{II}): \mathrm{Fe}(\mathrm{III})$ (green), and $\mathrm{Fe}(\mathrm{III})$ (red). The orange arrow indicates the presence of a second phase. PDF is obtained from X-ray total scattering data displaying b) local $r$-range 1.5-4 $\AA$ and c) intermediate-long $r$-range 4-50 A.

To complement the PDF data we performed microscopy analysis on the samples prepared using $\mathrm{Fe}(\mathrm{II})$ and $\mathrm{Fe}(\mathrm{III})$ precursors. First, we verified the inclusion of Mo atoms in the precipitated samples, by using Energy-dispersive X-ray (EDX) elemental mapping (Figure S1), which shows that Mo atoms are indeed homogeneously distributed at the particle level.

The sample prepared with the Fe(II) precursor was found to contain particles with two distinct sizes: larger than $100 \mathrm{~nm}$ and smaller than $50 \mathrm{~nm}$ (Figure 2), which could be in line with the occurrence of a second phase observed by XRD. Electron diffraction performed on several particles support the presence of two distinct phases with superposed diffraction rings indexed with $F d-3 m$ and $P_{4} 32$ space groups. The presence of two phases belonging to the abovementioned space groups is further corroborated by real-space Rietveld refinement of the PDF data 
(Figure S2). The refinement of the dampening of the PDF data also shows two distinct particle sizes, in good agreement with the XRD and microscopy analyses.

The sample prepared with the Fe(III) precursor was found to contain only very small particles with a narrow size distribution of 2-4 $\mathrm{nm}$ in diameter. Electron diffraction data for aggregated particles show diffuse rings, which are often considered to be characteristic of a disordered system (Figure 2b, inset). The HAADF image shows lattice fringes, however, which indicates that these particles consist of single well crystallized domains. Support for this interpretation comes from the PDF coherence length, which showed an average domain size of $2 \mathrm{~nm}$. We therefore attribute the diffuse scattering observed by XRD/ED to the small size of these particles, with additional broadening possibly due to micro-strains induced by the presence of Mo and vacancies as it will be further demonstrated.

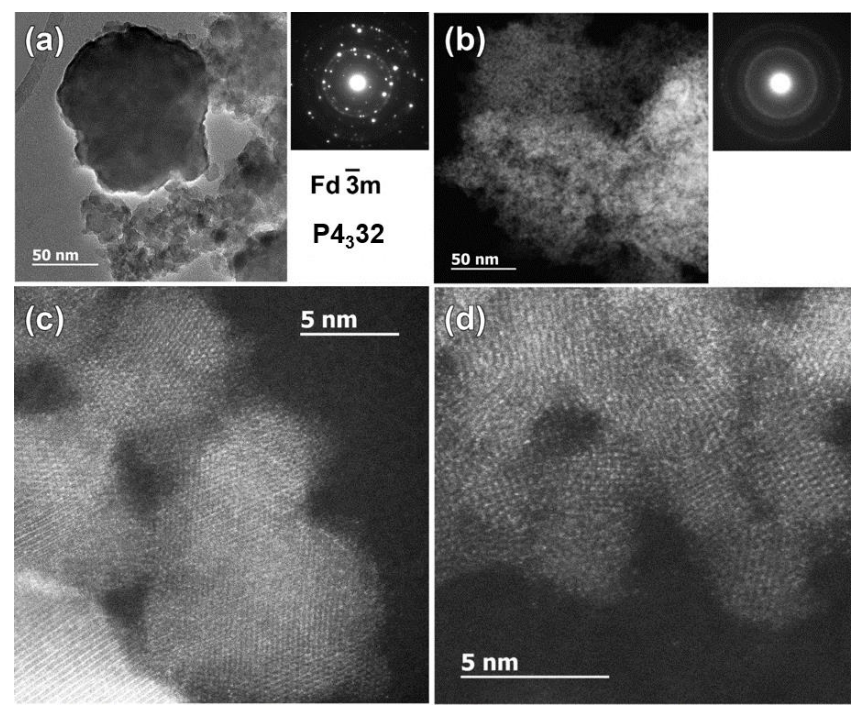

Figure 2. (a) Bright field TEM image of the sample prepared with Fe(II). Inset: electron diffraction indexed with $F d-3 m$ and $P_{3} 32$ space groups. (b) High-resolution HAADF-STEM image on particles of the sample prepared with Fe(III) precursor. Inset: electron diffraction showing diffuse scattering rings. (c) and (d) Magnified images of the samples prepared using the $\mathrm{Fe}(\mathrm{II})$ and $\mathrm{Fe}(\mathrm{III})$ precursors, respectively. 


\section{Structural analysis}

\section{${ }^{57}$ Fe Mössbauer spectroscopy}

To assess the iron oxidation state and local environments, we first used ${ }^{57} \mathrm{Fe}$ Mössbauer spectroscopy. Figure 3 shows the Mössbauer spectra recorded at $300 \mathrm{~K}$ of the three samples prepared from precursors containing iron in different oxidation states. For the sample synthesized from the $\mathrm{Fe}(\mathrm{II})$ precursor, the spectrum obtained can be refined with a distribution of magnetic fields with an isomer shift typical of trivalent iron, a paramagnetic doublet and finally an additional magnetic sextet with a higher isomer shift, of $0.88 \mathrm{~mm} / \mathrm{s}$. The latter represents iron in an intermediate state between $\mathrm{Fe}(\mathrm{II})$ and $\mathrm{Fe}(\mathrm{III})$, and corresponds to the rapid exchange between divalent and trivalent cations at the octahedral site of the magnetite. ${ }^{32}$ The reconstruction of the spectrum points to the presence of around $10 \%$ of $\mathrm{Fe}(\mathrm{II})$. The presence of a magnetic field distribution for most of the magnetic Fe(III) can result from the presence of a nanoparticle size distribution or structural defects. The presence of two different phases, evidenced by electron microscope measurements, cannot be distinguished by Mössbauer spectroscopy.

The spectrum of the sample prepared from the Fe(III) precursor shows a quadrupole doublet with a linewidth of about $0.5 \mathrm{~mm} / \mathrm{s}$. This spectral feature is typically observed for paramagnetic species or for magnetically ordered materials undergoing superparamagnetic relaxation at room temperature. In the latter case, rather typical when the material is made of particles with sizes lower than about $50 \mathrm{~nm}$, a doublet is obtained due to the relaxation of the magnetic moments of the nanoparticles, considered as single domains, under the influence of thermal agitation. ${ }^{33}$ Isomer shift and quadrupole splitting, of the order of 0.34 and $0.68 \mathrm{~mm} / \mathrm{s}$, respectively, are typical values for nanoparticles of iron(III) oxides or oxyhydroxides, including maghemite. ${ }^{32}$ 
The spectrum of the sample synthesized starting from mixed $\mathrm{Fe}(\mathrm{II}): \mathrm{Fe}(\mathrm{III})$ precursors can be interpreted with two components: a distribution of magnetic sextets with hyperfine fields between 30 and $48 \mathrm{~T}$, and a paramagnetic contribution which is simulated using two quadrupole doublets, with different isomers shifts typical of octahedral and tetrahedral trivalent iron, respectively.

Throughout the series, the evolution of the spectra can be described by the presence of a superparamagnetic component to which another magnetic component is added and becomes more and more intense as the proportion of divalent iron in the precursors increases, indicating a gradual increase of the particle size. Fe(II) is detected only in the sample obtained from Fe(II) precursors. The presence of magnetic field distributions makes it difficult to attribute unequivocally the contributions of octahedral and tetrahedral sites and their respective proportions, which can be assessed by x-ray absorption spectroscopy as shown below. 

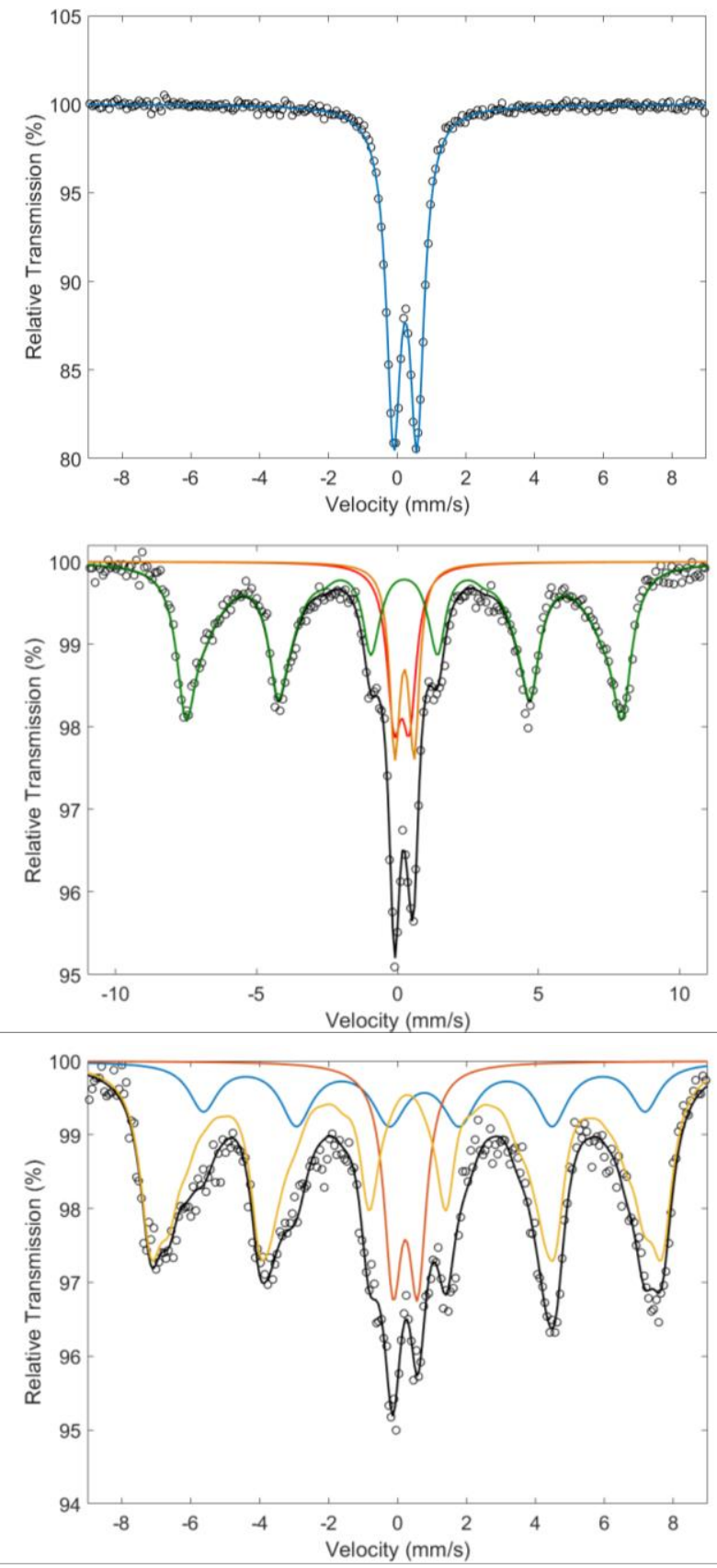

Figure 3. ${ }^{57} \mathrm{Fe}$ Mössbauer spectra of samples prepared using different iron precursors: from top to bottom: $\mathrm{Fe}(\mathrm{III}), \mathrm{Fe}(\mathrm{II})$ :Fe(III) and $\mathrm{Fe}(\mathrm{II})$.

Mo and Fe K-edge X-Ray absorption spectroscopy: XANES

The near-edge structure (XANES) of the XAS spectra at both Fe and Mo K-edges were used to assess the oxidation state and the local structure, respectively, of both molybdenum and iron 
centers in the synthesized oxides. The Mo K-edge XANES spectra of the three samples are gathered in Figure 4 (left). Depending on the nature of the precursor, we observed a noticeable difference in the position of the edge, which reflects variation in the oxidation state of Mo atoms. On one hand, the sample prepared with Fe(II) showed an edge position which is almost superimposed to that of $\mathrm{MoO}_{2}$ reference, indicating the presence of an average oxidation state of +4 . However, a linear combination fit of the XANES signature carried out using $\mathrm{MoO}_{2}$ and $\mathrm{MoO}_{3}$ as references for $\mathrm{Mo}(\mathrm{IV})$ and $\mathrm{Mo}(\mathrm{VI})$, respectively, provides a $\mathrm{Mo}(\mathrm{IV}) / \mathrm{Mo}(\mathrm{VI})$ ratio $~ 3$ (Figure S3). On the other hand, the introduction of Fe(III) is accompanied with an edge position shifted to higher energies, close to that of $\mathrm{MoO}_{3}$ and thus revealing an average oxidation state close to +6 . Concomitantly, the pre-edge peak located at $20007 \mathrm{eV}$ becomes more intense, which is associated with a $1 s-4 d$ transition characteristic of tetrahedral coordinated Mo. ${ }^{34,35}$ In the case of the sample prepared using $\mathrm{Fe}(\mathrm{III})$, this pre-peak became more intense suggesting the presence of a substantial amount of tetrahedrally coordinated Mo.
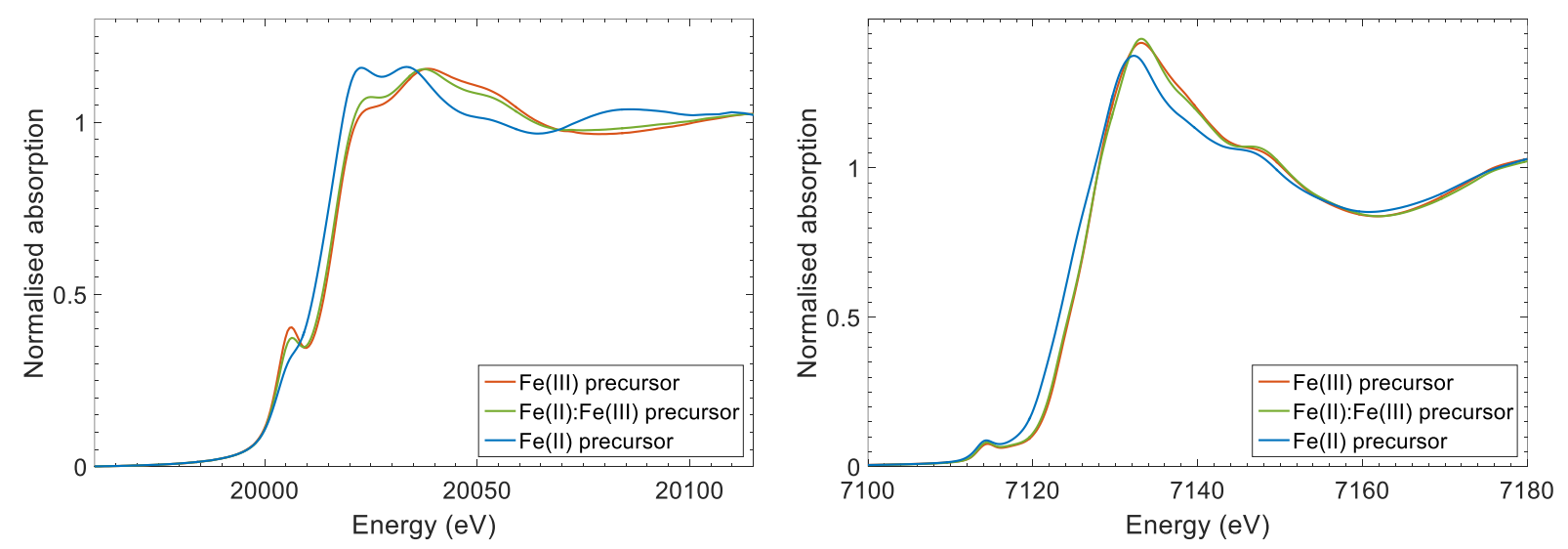

Figure 4. Mo (left) and Fe (right) K-edge XANES spectra of samples prepared using different iron precursors. 
The Fe-K XANES spectra (Figure 4, right) show a similar variation in Fe oxidation state with the choice of iron precursor. The XANES signals for the samples prepared from the pure Fe(III) and the mixed $\mathrm{Fe}(\mathrm{II}): \mathrm{Fe}(\mathrm{III})$ precursors are almost identical with an edge position shifted to higher energies compared to the sample prepared from pure Fe(II), indicating a lower average oxidation state for the latter. A comparison of the XANES signal with well-crystallized bulk hematite and maghemite references indicates that the samples prepared from the $\mathrm{Fe}(\mathrm{III})$ precursor contain mostly Fe(III) (Figure S4). The edge-shape is less defined than that of bulk crystalline materials, in line with the presence of nanosized/disordered particles. Even though less well defined, the different edge features (position of the main edge peaks) resemble those of the maghemite sample.

\section{Mo and Fe K-edge X-Ray absorption spectroscopy: EXAFS}

The Mo and Fe K-edge extended fine structure EXAFS portions of the XAS spectra, with their respective Fourier transforms are shown in Figure 5. The Mo K-edge spectra indicating that the Mo centers reside in very different environments in the different as-grown materials. The first shell of the sample prepared starting from Fe(II) precursors is shifted to high distances compared to the other two samples, in line with the lower oxidation state of the Mo observed in this sample. The first coordination shells of the samples prepared from $\mathrm{Fe}(\mathrm{II}): \mathrm{Fe}(\mathrm{III})$ and pure $\mathrm{Fe}(\mathrm{III})$ precursors indicates similar bond distances, but different intensity, which may reflect a difference in coordination number and/or disorder (different Debye-Waller factors). The second shell of the sample prepared from Fe(II) precursors is more intense than for the other two samples, indicating a decrease of the crystallinity in these samples on moving from pure $\mathrm{Fe}$ (II) to pure $\mathrm{Fe}$ (III) precursors. 

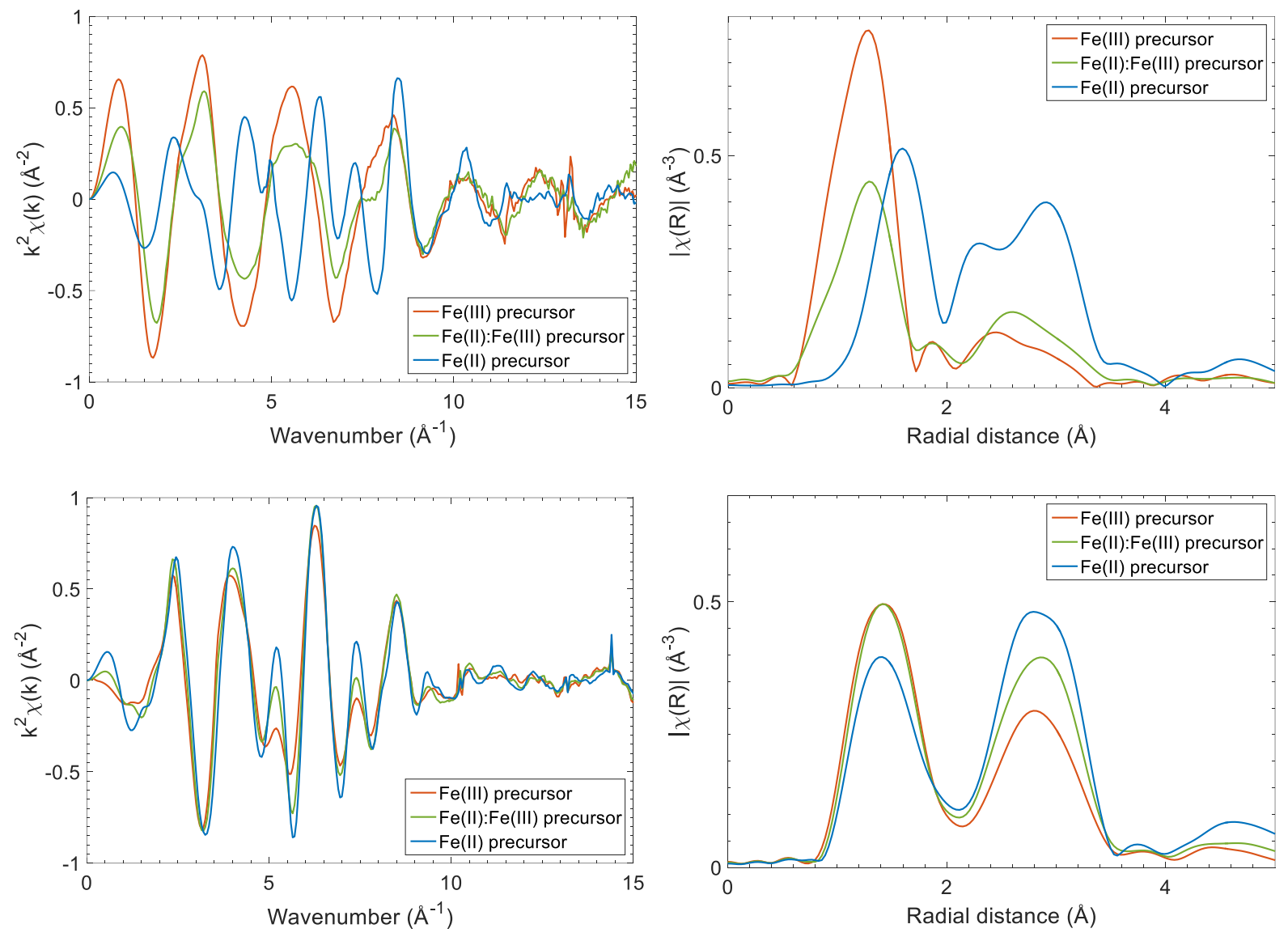

Figure 5. Mo (top) and Fe (bottom) K-edge EXAFS spectra of samples prepared using different iron precursors (left) and their corresponding phase-uncorrected Fourier transform (right).

More similar short-range environments are observed in the Fe K-edge XANES signatures, where the first coordination shell varies only slightly between the samples, and the second one decreases in intensity on going from the sample prepared with the Fe(II) precursor to that prepared with pure $\mathrm{Fe}(\mathrm{III})$. Furthermore, the decrease of this intensity is in line with the observed decrease in crystallinity in this series of samples.

To obtain more insight on the local structure around the Fe and Mo centers, the EXAFS spectra were analyzed starting from the simple spinel structure, and considering only oxygen and iron neighbors in the first and the second shell, respectively. Particular attention was paid to the first 
shell, which was interpreted by assuming the existence of a mixture of octahedral and tetrahedral coordination, for both Mo and Fe, implying a different number of neighbors and bond distances, and by fitting the respective population of the two bond sites. The fitting results, detailed in the SI section and summarized for the first coordination shell of Mo in Table 1, show that the majority of Mo occupies octahedral sites in the material obtained starting from Fe(II) precursors, and that increasingly populates the tetrahedral sites when the precursors contain increasing amounts of trivalent iron. The progressive inclusion of $\mathrm{Mo}(\mathrm{VI})$ in tetrahedral sites appears in contrast with its preferred coordination number. Based on the Inorganic Crystal Structure Database (ICSD), Brown calculated that the average observed coordination number was 4.88 and a predicted coordination number of 5.2. ${ }^{36}$ It is therefore expected that $\mathrm{Mo}(\mathrm{VI})$ atoms will preferentially adopt coordination number greater that four.

The iron occupation obtained by fitting the first shell of the Fe K-edge EXAFS spectra (Table 1 and S2) goes in the opposite direction: the relative population of the tetrahedral site by iron ions decrease on increasing the oxidation state of the precursors, in line with the increase in occupation of the tetrahedral sites by Mo ions. The global decrease in crystallinity is confirmed by the gradual increase of the Debye-Waller factors relative to the second coordination shell on going from Fe(II) to $\mathrm{Fe}(\mathrm{III})$ precursors. 


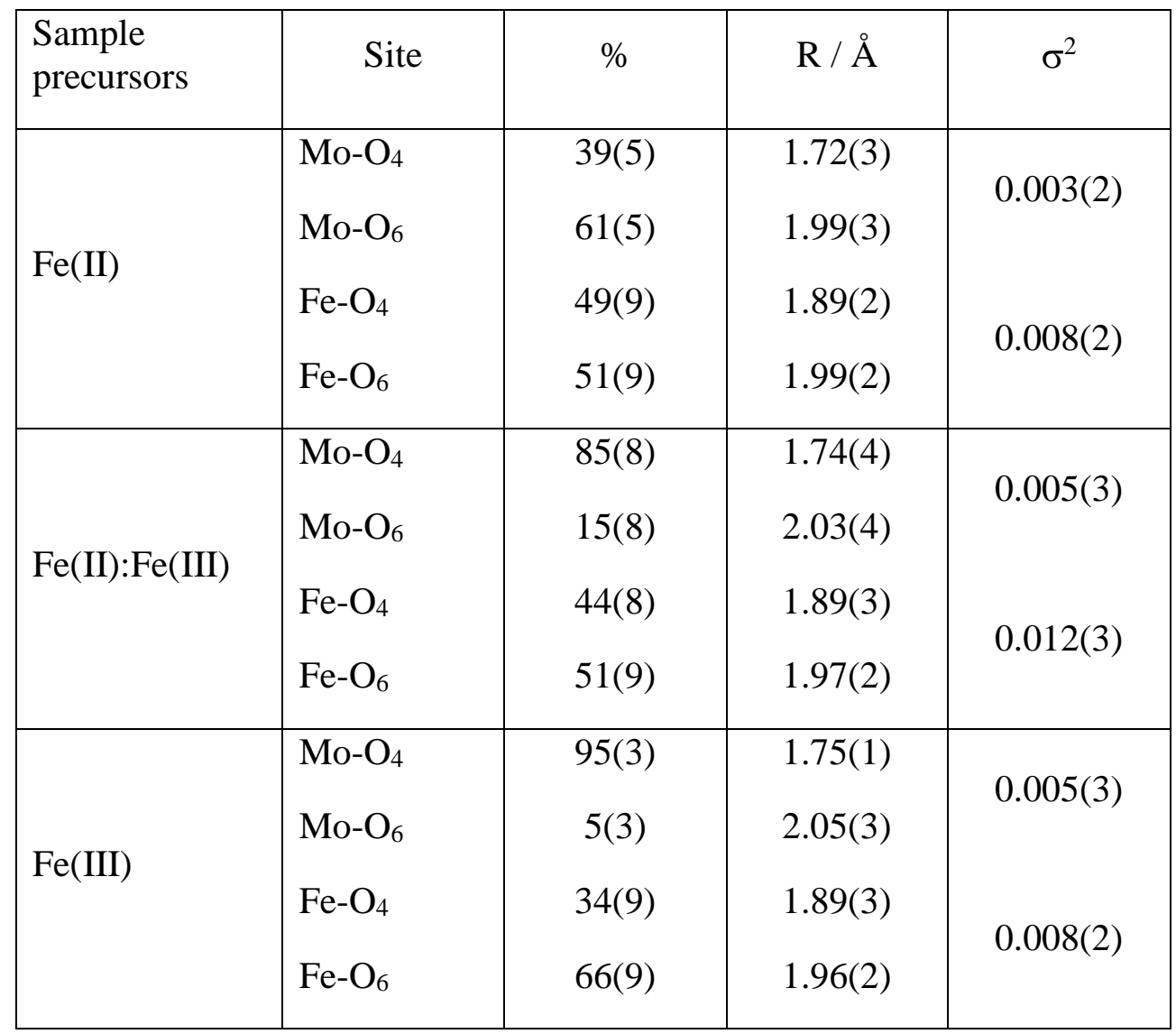

Table 1. Repartition of Mo and Fe in tetrahedral and octahedral sites in the studied materials obtained by refining the first coordination shell of the Mo and Fe K-edge EXAFS spectra.

\section{PDF refinement of the disordered spinel prepared with Fe(III) precursor}

The above results show that the sample prepared with Fe(III) consists of a pure single phase of ultra-small crystallized particles. The absence of Bragg peaks precludes the use of conventional $\mathrm{XRD}$, making this material a text book case for solving its complex nanostructure, known as the "nanostructure problem"37. In the so-called complex modelling, a self-consistent methodology consists of gathering various structural information provided by different measurements to build a model capturing all the key features spanning phase composition to local-, intermediate-range orders. ${ }^{38}$ We herein attempted to describe the atomic structure of such compound, by refining a starting model built from the phase composition and the local structure provided by XAS to the 
PDF data that includes local- and intermediate-range orders. The results of the fits were qualitatively assessed using the reliability factor $R_{\mathrm{w}}$.

At first, the phase composition was primary determined assuming that the substitution of one $\mathrm{Fe}^{\mathrm{III}}$ by one $\mathrm{Mo}^{\mathrm{VI}}$ was compensated by the formation of one vacancy according to $\mathrm{Fe}_{8 / 3-2 x} \mathrm{Mo}_{x} \square_{1 / 3+x} \mathrm{O}_{4}$. The Mo/Fe molar ratio determined by EDX was 0.21 (2) yielding $\mathrm{Fe}_{1.879} \mathrm{Mo}_{0.394} \square_{0.727} \mathrm{O}_{4}$. Note that this chemical composition was proposed to match electroneutrality and therefore does not take into account the standard deviation that need to be apply on the nominal composition.

We started by using the $F d-3 m$ space group, as a structural model with Mo and Fe atoms distributed according to the previously discussed EXAFS results. Considering the phase composition and EXAFS data together, we considered the following model $\left(\mathrm{Mo}_{0.373} \mathrm{Fe}_{0.637}\right)^{[8 \mathrm{a}]}\left(\mathrm{Mo}_{0.021} \mathrm{Fe}_{1.242}\right)^{[16 \mathrm{~d}]} \mathrm{O}_{4}$, where the $8 \mathrm{a}$ and 16b Wyckoff positions are the tetrahedral and octahedral cation sites, respectively. The refinement of the tetrahedral site occupancy confirmed that it is fully occupied ruling out tetrahedral vacancies. The final fit only partially reproduces the experimental PDF features with a relatively high reliability factor $R_{\mathrm{w}}$ of $37.7 \%$ (shown in Figure 6a). Because this model uses the $F d-3 m$ space group, the refinement cannot capture local structure effects such as those due to vacancy ordering, as has been suggested by Lappas et $a l .{ }^{39}$. To allow for this effect, we next considered a lower symmetry space group $\left(\mathrm{P}_{3} 32\right)$ for the refinement model. In the $P 4_{3} 32$ structure, there is one tetrahedral site (8c Wyckoff site) and two non-equivalent octahedral sites (4b and 12d Wyckoff sites) with the cationic vacancies being preferentially located on the $4 \mathrm{~b}$ site, i.e., $\left(\mathrm{Fe}_{0.33} \square_{0.66}\right)_{0.5}^{[4 \mathrm{~b}]} \cdot{ }^{40}$ For this refinement, our previous model was to $\left(\mathrm{Mo}_{0.373} \mathrm{Fe}_{0.637}\right)^{[8 \mathrm{c}]}\left(\mathrm{Fe}_{0.33} \square_{0.66}\right)^{[4 b]}\left(\mathrm{Mo}_{0.021} \mathrm{Fe}_{0.912}\right)^{[16 d]} \mathrm{O}_{4}$. The additional refinement of the $4 \mathrm{~b}$ site occupancy improved the fit to the data, resulting in the absence of atoms within this site. 
Moreover, we attempted to refine the Mo/Fe occupancy. This resulted in high estimated standard deviation suggesting that it is poorly sensitive to the Mo/Fe occupancy, probably due to the limited range order. The final fit shown in Figure $\mathbf{6 b}$, resulted in a much better agreement with the experimental data $\left(R_{\mathrm{w}}=23.9 \%\right.$ vs. $37.7 \%$ for the $F d-3 m$ model $)$ highlighting a vacancy ordering.

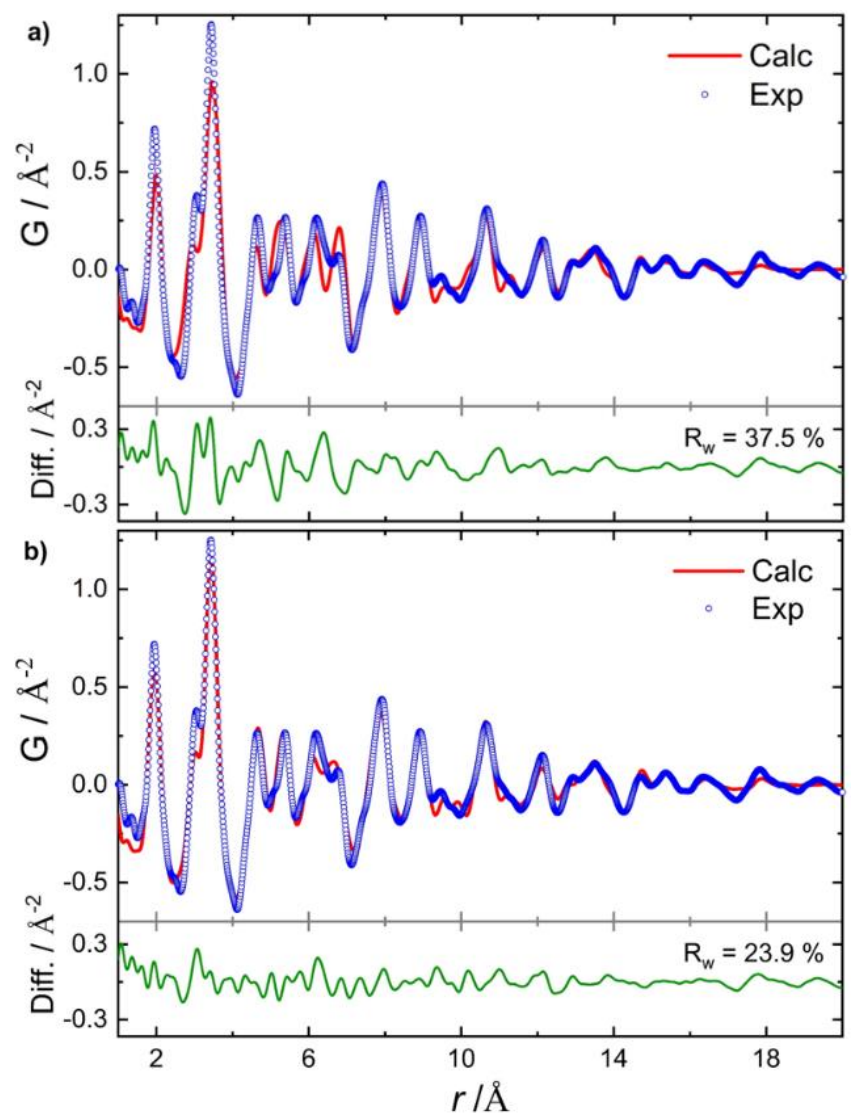

Figure 6. Refinements of the PDF data of the sample prepared with Fe(III) precursor using a) $F d$ $3 m$ and b) $P 4332$ space group as structural models.

\section{DFT-calculations}

As stated above, in inorganic structure it is expected that $\mathrm{Mo}(\mathrm{VI})$ atoms will preferentially adopt coordination number greater that four. To better understand both the thermodynamic site preference of $\mathrm{Mo}(\mathrm{VI})$ and the structural impact of Mo inclusion within the spinel structure, we 
used Density Functional Theory (DFT). We first assessed the thermodynamic site preference of a $\mathrm{Mo}$ (VI) dopant in $\mathrm{Fe}_{2} \mathrm{O}_{3}$. We calculated the formation energy of all possible $\mathrm{Mo}_{\mathrm{Fe}}$ defects in the vacancy ordered $P 4_{1} 2{ }_{1} 2$ structure. ${ }^{41}$ The relative energies of each defect as a function of Fermi level are plotted in Figure 7. Our calculations predict that Mo preferentially occupies octahedral rather than tetrahedral sites under all chemical conditions (at all Fermi energies), in agreement with the expected coordination number ${ }^{36}$.

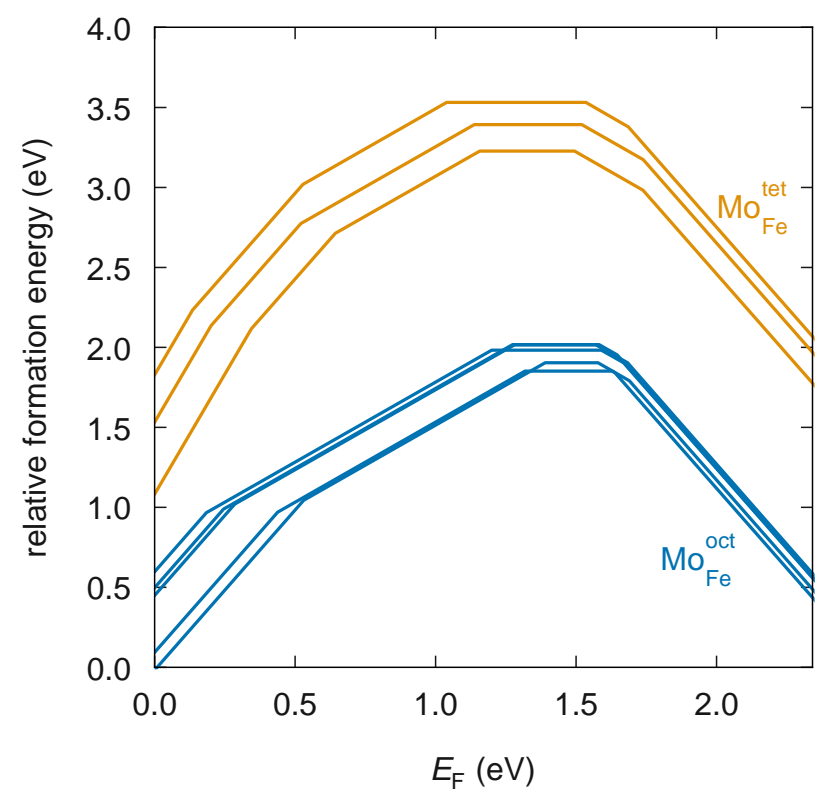

Figure 7. Relative formation energies of all possible $\mathrm{Mo}_{\mathrm{Fe}}$ defects in vacancy ordered $\mathrm{Fe}_{2} \mathrm{O}_{3}$, where formation energies of all defects are reported relative to the lowest energy defect at $E_{\mathrm{F}}=0$.

The local coordination around lowest energy $\mathrm{Mo}_{\mathrm{Fe}}^{\text {oct }}$ and $\mathrm{Mo}_{\mathrm{Fe}}^{\text {tet }}$ defects with a charge of +3 , i.e., $\mathrm{Mo}_{\mathrm{Fe}}^{\cdots \cdot}$ (corresponding to $\mathrm{Mo}(\mathrm{VI})$ occupying an $\mathrm{Fe}(\mathrm{III})$ site) are shown in Figure 8 compared to the local structure around Fe in the defect-free cell. There is a clear distortion of ideal octahedral and tetrahedral symmetry both before and after Mo insertion. The increased positive charge of the Mo relative to Fe causes the oxygen ions to contract around it. This trend is in good agreement with 
the experimental data obtained by EXAFS fitting with average distances of $1.75 \AA$ for Mo- $\mathrm{O}_{4}$ (vs. $1.77 \AA$ from DFT) and $1.89 \AA$ for $\mathrm{Fe}_{-} \mathrm{O}_{4}(v s .1 .88 \AA$ from DFT).
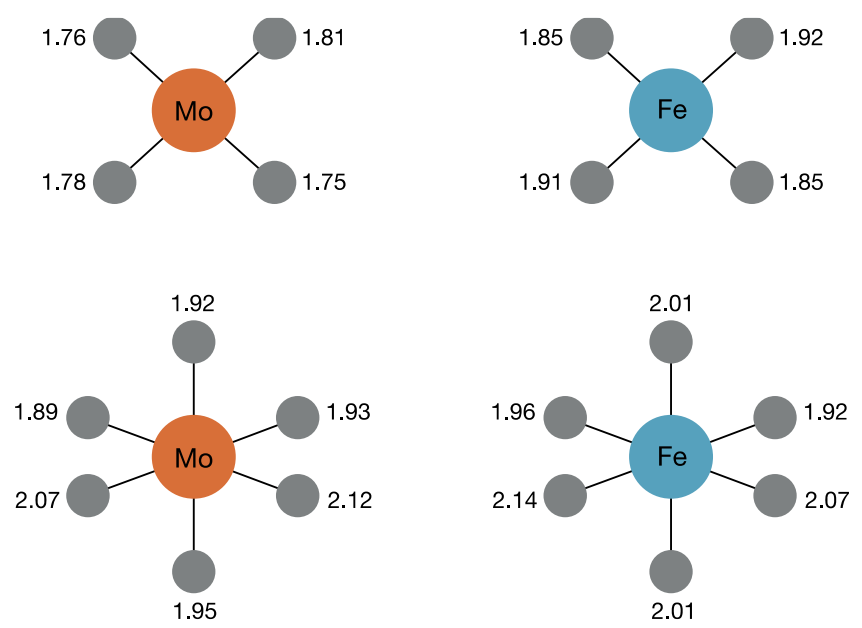

Figure 8. Local coordination environments around $\mathrm{Mo}_{\mathrm{Fe}}^{\bullet \bullet}$ defects (shown in orange) for both the lowest energy octahedral and tetrahedral defect calculated from DFT, also shown is the local coordination environment around the Fe that occupies the same site in the pristine structure (shown in blue) all distances are given in Angstroms.

\section{Discussion}

The composition of the crystallization solution tuned by means of the iron oxidation state precursor was shown to greatly influence the chemistry of the as-grown materials. For Mo atoms, the oxidation state varies in the final materials with $\mathrm{Mo}^{\mathrm{IV}} / \mathrm{Mo}^{\mathrm{VI}}$ when using $\mathrm{Fe}(\mathrm{II})$ to $\mathrm{Mo}^{\mathrm{VI}}$ when introducing $\mathrm{Fe}(\mathrm{III})$ precursor. That being said, the oxidation state of the Mo precursor $\left(\mathrm{MoCl}_{5}\right)$, that is $+\mathrm{V}$, is not recovered in the final material. Moreover, only the sample prepared with Fe(II) precursor contains $\mathrm{Fe}(\mathrm{II})$ and only in a small proportion (10\%). According to standard potentials, $\mathrm{Fe}^{2+}$ and $\mathrm{Mo}^{5+}$ ions can be oxidized by $\mathrm{O}_{2}\left(\mathrm{E}^{\circ}\left(\mathrm{Fe}^{3+} / \mathrm{Fe}^{2+}\right): 0.77 \mathrm{~V}, \mathrm{E}^{\circ}\left(\mathrm{Mo}^{6+} / \mathrm{Mo}^{5+}\right): 0.43 \mathrm{~V}\right.$ vs. $\mathrm{NHE}$, $\mathrm{E}^{\circ}\left(\mathrm{O}_{2} / \mathrm{H}_{2} \mathrm{O}\right): 1.23 \mathrm{~V}$ vs. NHE). The presence of reduced $\mathrm{Mo}(\mathrm{IV})$ is therefore counter-intuitive with 
the chemistry of the crystallizing solution. Rellán-Piñeiro et $a l^{42}$, however, have shown that two $\mathrm{Mo}(\mathrm{V})$ could disproportionate to $\mathrm{Mo}(\mathrm{VI})$ and $\mathrm{Mo}(\mathrm{IV})$ centers because the later reaction is energetically neutral, providing a possible explanation for the reduced state of Mo atoms.

We further underlined that the solution chemistry affects the growth of the particles with sizes ranging from 40-100 nm with Fe(II) precursor to 2-4 nm with Fe(III). Additionally, we observed a variation of the cation distribution in tetrahedral and octahedral sites of the spinel structure: the relative population of the tetrahedral site by iron ions decrease on increasing the oxidation state of the precursors and concomitantly, the occupation of the tetrahedral sites by Mo ions increases. There seems to be a relationship between the particle size and the coordination mode of Mo(VI). Tetrahedral vacancies are known to be reactive species at the surface of iron oxide nanoparticles, further promoting growth. ${ }^{16,17}$ We hypothesized that populating tetrahedral sites with Mo(VI) can affect the growth of the particles by blocking these reactive sites. To support our hypothesis, we conducted a synthesis using an equimolar ratio of $\mathrm{Fe}(\mathrm{II})$ and $\mathrm{Fe}(\mathrm{III})$ without Mo. The synthetized product appears to be well crystallized in contract with the material prepared with Mo (Figure S7). Further insight into the role of Mo ions on the growth of nanoparticles were obtained by comparing the PDF data obtained on the sample prepared with and without Mo ions (Figure 9). Notably, it shows that the presence of Mo ions induced shorter inter-atomic distances (Figure 9a), in good agreement with DFT-calculations, further emphasizing a contraction of the crystalline lattice. Moreover, the occurrence of distinct PDF features at long-range order (Figure 9b), i.e., r > $15 \AA$, for the sample prepared without Mo ions, is indicative of larger particles, further supporting the impact of Mo ions in the growth of iron oxide nanoparticles. Accordingly, we concluded that the synthetized compound featuring Mo(VI) in tetrahedral sites affects the growth of the particles so that the structure can be considered "kinetically trapped". ${ }^{43}$ Overall, our findings appear to be 
particularly interesting to better describe the chemistry of nucleation of complex systems, which might be used to better understand non-classical nucleation models. ${ }^{12}$ The results highlight the interplay between the chemistry of crystallization solution and the structural features of the formed material.
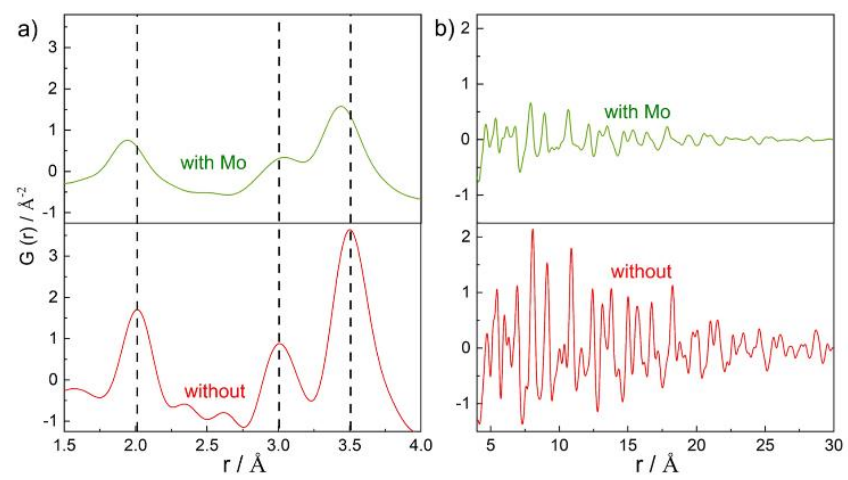

Figure 9. PDF data obtained for the sample prepared with and without Mo ions: a) local $r$-range 1.5-4 $\AA$ and b) intermediate-long $r$-range $4-30 \AA$.

\section{CONCLUSION}

Solution chemistry was shown to have a strong impact on the compositional/structural and morphological aspects of Mo-substituted iron oxide nanoparticles. By tuning the nature of the Fe precursor on going from $\mathrm{Fe}(\mathrm{II})$ to an equimolar ratio of $\mathrm{Fe}(\mathrm{II}): \mathrm{Fe}(\mathrm{III})$, and lastly to $\mathrm{Fe}(\mathrm{III})$, a progressive decrease of the atomic-range order was observed, associated with the contraction of the particle size when introducing $\mathrm{Fe}(\mathrm{III})$. Moving from $\mathrm{Fe}(\mathrm{II})$ to $\mathrm{Fe}(\mathrm{III})$ precursors induces a variation of the cation distribution in tetrahedral and octahedral sites of the spinel structure: the relative population of the tetrahedral site by iron ions decrease on increasing the oxidation state of the precursors and concomitantly, the occupation of the tetrahedral sites by Mo ions increases. The occupancy of Mo ions within the tetrahedral site is kinetically driven and hypothesized to be 
responsible for the stabilization of small particles by blocking reactive sites, as further supported by a blank experiment without Mo ions.

\section{EXPERIMENTAL AND COMPUTATIONAL METHODS}

Synthesis. The synthesis method employed was adapted from the protocol previously proposed by Hahn et $a l^{21}$. The nominal molar ratio Mo/Fe was fixed to 0.19 and the molar quantity of cations were $8.10^{-4} \mathrm{~mol}$ for Mo and $4.17 .10^{-3} \mathrm{~mol}$ for Fe. In a typical experiment, molybdenum chloride $\left(\mathrm{MoCl}_{5}\right.$, Sigma-Aldrich, $\left.95 \%\right)$ and ferrous chloride $\left(\mathrm{FeCl}_{2} .4 \mathrm{H}_{2} \mathrm{O}\right.$, Sigma-Aldrich, $\left.100 \%\right)$ were dissolved in $15 \mathrm{~mL}$ of absolute ethanol. Ferric chloride (Sigma-Aldrich, $97 \%$ ) was dissolved in $10 \mathrm{~mL}$ of deionized water. The two solutions were then mixed together and $3.45 \mathrm{~mL}$ of N,Ndiethylethanamine $\left(\left(\mathrm{C}_{2} \mathrm{H}_{5}\right)_{3} \mathrm{~N}\right.$, Sigma-Aldrich, $\left.98 \%\right)$ was added. The solution was then put in autoclave and heated at $90^{\circ} \mathrm{C}$ for 12 hours, washed several times with a mixture of deionized water and absolute ethanol, and the resulting powders were finally dried at $100^{\circ} \mathrm{C}$ for 4 hours prior to any characterizations. In a typical synthesis, around $400 \mathrm{mg}$ of powder was obtained.

X-ray diffraction (XRD) and Transmission Electron Microscopy (TEM) analyses. Powder XRD patterns were recorded on PANalytical X'Pert ( $\mathrm{Co}-\mathrm{K} \alpha$ or $\mathrm{Cu}-\mathrm{K} \alpha_{1}$ radiations) diffractometers in a Bragg-Brentano geometry $(\theta-2 \theta)$.

TEM analysis was performed using a JEM ARM200F FEG double aberration corrected microscope operated at $200 \mathrm{kV}$, equipped with CENTURIO EDX detector and GIF Quantum. The sample was prepared in a glove box by suspending the powder in methanol and deposited it on holey carbon $\mathrm{Cu}$ grid. Afterwards the grid was immediately transport inside the microscope.

Mössbauer spectroscopy. The ${ }^{57}$ Fe Mössbauer spectra were measured at room temperature (293 $\mathrm{K})$ with a ${ }^{57} \mathrm{Co} / \mathrm{Rh}$ source and a $\mathrm{Kr}$ gas proportional counter. The spectrometer was operated with 
a triangular velocity waveform and the spectra were fitted with superpositions of appropriate sets of Lorentzian lines using the PC-MOS computer program. ${ }^{44}$ The resulting parameters such as the magnetic hyperfine field $\mathrm{B}_{\mathrm{hf}}$, the electric quadrupole splitting $\Delta$, the isomer shift $\delta$ (given relative to $\alpha-\mathrm{Fe}$ ), and the resonance area in percent of the total iron are listed in Table S3.

X-ray absorption spectroscopy. Fe and Mo K-edge X-ray absorption spectroscopy (XAS) data were collected at room temperature at the beamline ROCK, Synchrotron SOLEIL (France) on selfsupported pellets of the measured materials of appropriate thickness. Extended X-ray absorption Fine Structure (EXAFS) spectra were extracted with the standard procedure using Athena and fitted using Artemis, both programs being included in the Demeter software package. ${ }^{45}$ Fourier transforms of EXAFS oscillations were carried out from 0.25 to $1.1 \mathrm{~nm}^{-1}$ using a sine window. Fitting was performed in the $R$-range from 0.1 to $0.35 \mathrm{~nm}$ using $k^{1}, k^{2}$ and $k^{3}$ weights.

Pair Distribution Function (PDF) analysis. High energy X-ray data were collected at the 11-IDB station at the Advanced Photon Source (Argonne National Laboratory). After corrections (background and Compton scattering), PDFs were extracted from the data using PDFgetX2 sofware. ${ }^{46}$ Refinements of the PDF data were performed using PDFgui. ${ }^{47}$ The quality of the refinement is quantified by the reliability factor weighted $\mathrm{R}$-value, denoted as $\mathrm{R}_{w}$. The $\mathrm{R}$-value describes the difference between the experimental observation (data) and the calculated value (fit) for a single data point. The $\mathrm{R}_{w}$ is the $\mathrm{R}$-value weighted for data point $i$, and is given by the formula:

$$
\mathrm{R}_{w}=\sqrt{\frac{\sum_{i=1}^{\mathrm{N}} w\left(r_{i}\right)\left[\mathrm{G}_{o b s}\left(r_{i}\right)-\mathrm{G}_{c a l c}\left(r_{i}\right)\right]^{2}}{\sum_{i=1}^{\mathrm{N}} w\left(r_{i}\right) \mathrm{G}_{o b s}^{2}\left(r_{i}\right)}}
$$

with $\mathrm{G}_{o b s}$ and $\mathrm{G}_{c a l c}$ being the observed (data) and calculated (fit) PDF and $w\left(r_{i}\right)$ the weight for each data point. 
Computational methods. Density functional theory (DFT) calculations were performed using VASP. ${ }^{48-50}$ Valence electrons were described by a plane-wave basis with a kinetic energy cut-off of $520 \mathrm{eV}$, this was increased to $700 \mathrm{eV}$ for any calculations which allowed cell volume to vary, minimising errors arising due to Pulay stress. ${ }^{51}$ Interactions between core and valence electrons were described using the projector augmented wave (PAW) method, ${ }^{52,53}$ with valence electron configurations of $4 p^{6} 5 s^{2} 4 d^{4}$ for Mo, $2 s^{2} 2 p^{4}$ for $\mathrm{O}$, and $3 p^{6} 3 d^{7} 4 s^{1}$ for Fe. Calculations used the generalized gradient approximation functional $\mathrm{PBEsol}^{54}$, with a Dudarev $+U$ correction applied to the Fe and Mo $d \operatorname{states}^{55}\left(U_{\mathrm{Fe}}=5.3 \mathrm{eV}, U_{\mathrm{Mo}}=4.38 \mathrm{eV}\right)^{56}$. All calculations were spin-polarised; magnetic moments on tetrahedral $\mathrm{Fe}$ were initialised in the opposite direction to those on octahedral $\mathrm{Fe}$, to describe the ferrimagnetic behaviour of $\mathrm{Fe}_{2} \mathrm{O}_{3}{ }^{57}$

$\mathrm{Mo}_{\mathrm{Fe}}$ defect formation energies $\left(\Delta E_{\mathrm{f}}^{\mathrm{MoFe}}\right)$ are calculated according to

$$
\Delta E_{\mathrm{f}}^{\mathrm{MoFe}}=E_{\mathrm{tot}}^{\mathrm{MoFe}}-E_{\mathrm{tot}}^{\mathrm{Fe} 2 \mathrm{O} 3}-\Delta \mu_{\mathrm{Fe}}+\Delta \mu_{i}+q\left(E_{\mathrm{F}}+E_{\mathrm{vbm}}^{\mathrm{Fe} 2 \mathrm{O}}\right)+E_{\mathrm{corr}}^{q}
$$

where $E_{\mathrm{tot}}^{\mathrm{MoFe}}$ is the total energy of a calculation containing one $\mathrm{Mo}_{\mathrm{Fe}}$ defect, $E_{\mathrm{tot}}^{\mathrm{Fe} 2 \mathrm{O}}$ is the total energy of the host material, $\Delta \mu_{\mathrm{Fe}}$ and $\Delta \mu_{\mathrm{Mo}}$ are the chemical potentials of Fe and Mo respectively, $q$ is the defect charge state, $E_{\mathrm{F}}$ is the Fermi energy aligned to the valence band maximum of the host cell $E_{\mathrm{vbm}}^{\mathrm{Fe} 2 \mathrm{O} 3}$ and $E_{\text {corr }}^{q}$ is a correction term account for finite-cell effects. ${ }^{58-60}$ The formation energies of $\mathrm{Mo}_{\mathrm{Fe}}$ defects are calculated for all integer charge states between $\mathrm{Mo}_{\mathrm{Fe}}$ and $\mathrm{Mo}_{\mathrm{Fe}} \mathrm{DFT}$ calculation inputs and outputs, are available in the associated dataset. Here we are interested in the relative energies of defect formation at octahedral and tetrahedral sites, rather than calculating defect formation energy as a function of atomic chemical potential. We therefore calculated formation energies relative to the lowest energy MoFe defect and treated the Fermi energy as a free parameter. 
DFT calculation inputs and outputs are available in the associated dataset. ${ }^{61}$ This analysis used the open-source python packages Numpy ${ }^{62}$, Pymatgen ${ }^{63}$, Matplotlib ${ }^{64}$, Scipy ${ }^{65}$, vasppy ${ }^{66}$ and a Python implementation of the Fortran code sc-Fermi ${ }^{67}$, which is available at Ref ${ }^{68}$.

\section{ASSOCIATED CONTENT}

Supporting Information. HAADF-STEM images and EDX elemental mapping, PDF refinement, XANES spectra of reference samples, Mo and Fe K-edge XAS fitting procedure and corresponding fits, ${ }^{57} \mathrm{Fe}$ hyperfine parameters obtained by fitting the ${ }^{57} \mathrm{Fe}$ Mössbauer data.

\section{ACKNOWLEDGMENTS}

RS2E and DGA are gratefully acknowledged for financing for a $\mathrm{PhD}$ grant of $\mathrm{CH}$. The work done at the Advanced Photon Source, an Office of Science User Facility operated for the U.S. Department of Energy (DOE) Office of Science by Argonne National Laboratory, was supported by the U.S. DOE under Contract No. DE-AC02-06CH11357. B. J. M. acknowledges support from the Royal Society (Grant No. UF130329), and the Faraday Institution (faraday.ac.uk; EP/S003053/1, grant number FIRG003). Calculations were performed using the Balena High Performance Computing Service at the University of Bath, and the ARCHER supercomputer, through membership of the UK's HPC Materials Chemistry Consortium, funded by EPSRC grant EP/L000202. XAS measurements were performed at the beamline ROCK of synchrotron Soleil (Gif-sur-Yvette, France). Synchrotron Soleil (France) is acknowledged for providing beamtime at the beamline ROCK. S. Belin and V. Briois are gratefully acknowledged for their expert advice on beamline operation. This work was supported by two public grants overseen by the French National Research Agency (ANR) as part of the "Investissements d'Avenir" program (Projects ANR-10-EQPX-45 (Equipex ROCK) and ANR-10-LABX-76-01 (Labex STOREX)). 


\section{REFERENCES}

(1) Xia, Z.; Poeppelmeier, K. R. Chemistry-Inspired Adaptable Framework Structures. Acc. Chem. Res. 2017, 50 (5), 1222-1230.

(2) Liu, M.; Rong, Z.; Malik, R.; Canepa, P.; Jain, A.; Ceder, G.; A. Persson, K. Spinel Compounds as Multivalent Battery Cathodes: A Systematic Evaluation Based on Ab Initio Calculations. Energy \& Environmental Science 2015, 8 (3), 964-974.

(3) Greaves, C. A Powder Neutron Diffraction Investigation of Vacancy Ordering and Covalence in $\gamma-\mathrm{Fe}_{2} \mathrm{O}_{3}$. Journal of Solid State Chemistry 1983, 49 (3), 325-333.

(4) Shmakov, A. N.; Kryukova, G. N.; Tsybulya, S. V.; Chuvilin, A. L.; Solovyeva, L. P. Vacancy Ordering in $\gamma-\mathrm{Fe}_{2} \mathrm{O}_{3}$ : Synchrotron X-Ray Powder Diffraction and High-Resolution Electron Microscopy Studies. J Appl Cryst 1995, 28 (2), 141-145.

(5) Jørgensen, J.-E.; Mosegaard, L.; Thomsen, L. E.; Jensen, T. R.; Hanson, J. C. Formation of $\gamma-\mathrm{Fe}_{2} \mathrm{O}_{3}$ Nanoparticles and Vacancy Ordering: An in Situ X-Ray Powder Diffraction Study. Journal of Solid State Chemistry 2007, 180 (1), 180-185.

(6) Petkov, V.; Cozzoli, P. D.; Buonsanti, R.; Cingolani, R.; Ren, Y. Size, Shape, and Internal Atomic Ordering of Nanocrystals by Atomic Pair Distribution Functions: A Comparative Study of $\gamma-\mathrm{Fe}_{2} \mathrm{O}_{3}$ Nanosized Spheres and Tetrapods. J. Am. Chem. Soc. 2009, 131 (40), $14264-14266$.

(7) Baumgartner, J.; Dey, A.; Bomans, P. H. H.; Le Coadou, C.; Fratzl, P.; Sommerdijk, N. A. J. M.; Faivre, D. Nucleation and Growth of Magnetite from Solution. Nature Materials 2013, 12 (4), 310-314.

(8) Scheck, J.; Wu, B.; Drechsler, M.; Rosenberg, R.; Van Driessche, A. E. S.; Stawski, T. M.; Gebauer, D. The Molecular Mechanism of Iron(III) Oxide Nucleation. J. Phys. Chem. Lett. 2016, 7 (16), 3123-3130.

(9) Sun, S.; Gebauer, D.; Cölfen, H. Alignment of Amorphous Iron Oxide Clusters: A NonClassical Mechanism for Magnetite Formation. Angewandte Chemie International Edition 2017, 56 (14), 4042-4046.

(10) Das, B. Theoretical Study of Small Iron-Oxyhydroxide Clusters and Formation of Ferrihydrite. J. Phys. Chem. A 2018, 122 (2), 652-661.

(11) Zhang, H.; Waychunas, G. A.; Banfield, J. F. Molecular Dynamics Simulation Study of the Early Stages of Nucleation of Iron Oxyhydroxide Nanoparticles in Aqueous Solutions. $J$. Phys. Chem. B 2015, 119 (33), 10630-10642.

(12) Bøjesen, E. D.; Iversen, B. B. The Chemistry of Nucleation. CrystEngComm 2016, 18 (43), 8332-8353.

(13) Lee, J.; Yang, J.; Kwon, S. G.; Hyeon, T. Nonclassical Nucleation and Growth of Inorganic Nanoparticles. Nature Reviews Materials 2016, 1 (8), 1-16.

(14) Gebauer, D.; Wolf, S. E. Designing Solid Materials from Their Solute State: A Shift in Paradigms toward a Holistic Approach in Functional Materials Chemistry. J. Am. Chem. Soc. 2019, 141 (11), 4490-4504.

(15) Jolivet, J.-P.; Cassaignon, S.; Chanéac, C.; Chiche, D.; Durupthy, O.; Portehault, D. Design of Metal Oxide Nanoparticles: Control of Size, Shape, Crystalline Structure and Functionalization by Aqueous Chemistry. Comptes Rendus Chimie 2010, 13 (1), 40-51. 
(16) Auffan, M.; Rose, J.; Proux, O.; Borschneck, D.; Masion, A.; Chaurand, P.; Hazemann, J.L.; Chaneac, C.; Jolivet, J.-P.; Wiesner, M. R.; Van Geen, A.; Bottero, J.-Y. Enhanced Adsorption of Arsenic onto Maghemites Nanoparticles: As(III) as a Probe of the Surface Structure and Heterogeneity. Langmuir 2008, 24 (7), 3215-3222.

(17) Cooper, S. R.; Candler, R. O.; Cosby, A. G.; Johnson, D. W.; Jensen, K. M. Ø.; Hutchison, J. E. Evolution of Atomic-Level Structure in Sub-10 Nanometer Iron Oxide Nanocrystals: Influence on Cation Occupancy and Growth Rates. ACS Nano 2020, 14 (5), 5480-5490.

(18) Jolivet, J. P.; Belleville, P.; Tronc, E.; Livage, J. Influence of Fe(II) on the Formation of the Spinel Iron Oxide in Alkaline Medium. Clays Clay Miner. 1992, 40 (5), 531-539.

(19) Ruetschi, P.; Giovanoli, R. Cation Vacancies in $\mathrm{MnO}_{2}$ and Their Influence on Electrochemical Reactivity. J. Electrochem. Soc. 1988, 135 (11), 2663.

(20) Swider-Lyons, K. E.; Love, C. T.; Rolison, D. R. Improved Lithium Capacity of Defective $\mathrm{V}_{2} \mathrm{O}_{5}$ Materials. Solid State Ionics 2002, 152-153, 99-104.

(21) Hahn, B. P.; Long, J. W.; Mansour, A. N.; Pettigrew, K. A.; Osofsky, M. S.; Rolison, D. R. Electrochemical Li-Ion Storage in Defect Spinel Iron Oxides: The Critical Role of Cation Vacancies. Energy Environ. Sci. 2011, 4 (4), 1495-1502.

(22) Koo, B.; Xiong, H.; Slater, M. D.; Prakapenka, V. B.; Balasubramanian, M.; Podsiadlo, P.; Johnson, C. S.; Rajh, T.; Shevchenko, E. V. Hollow Iron Oxide Nanoparticles for Application in Lithium Ion Batteries. Nano Lett. 2012, 12 (5), 2429-2435.

(23) Koo, B.; Chattopadhyay, S.; Shibata, T.; Prakapenka, V. B.; Johnson, C. S.; Rajh, T.; Shevchenko, E. V. Intercalation of Sodium Ions into Hollow Iron Oxide Nanoparticles. Chem. Mater. 2013, 25 (2), 245-252.

(24) Li, W.; Corradini, D.; Body, M.; Legein, C.; Salanne, M.; Ma, J.; Chapman, K. W.; Chupas, P. J.; Rollet, A.-L.; Julien, C.; Zhagib, K.; Duttine, M.; Demourgues, A.; Groult, H.; Dambournet, D. High Substitution Rate in $\mathrm{TiO}_{2}$ Anatase Nanoparticles with Cationic Vacancies for Fast Lithium Storage. Chem. Mater. 2015, 27 (14), 5014-5019.

(25) Gao, P.; Metz, P.; Hey, T.; Gong, Y.; Liu, D.; Edwards, D. D.; Howe, J. Y.; Huang, R.; Misture, S. T. The Critical Role of Point Defects in Improving the Specific Capacitance of $\delta-\mathrm{MnO}_{2}$ Nanosheets. Nature Communications 2017, 8, 14559.

(26) Ahmed, S. I.; Heiba, Z. K.; Mostafa, N. Y.; Shaltout, A. A.; Aljoudy, H. S. The Role of High-Valent (Mo and V) Cations in Defect Spinel Iron Oxide Nanomaterials: Toward Improving Li-Ion Storage. Ceramics International 2018, 44 (17), 20692-20699.

(27) Hahn, B. P.; Long, J. W.; Rolison, D. R. Something from Nothing: Enhancing Electrochemical Charge Storage with Cation Vacancies. Accounts of Chemical Research 2013, 46 (5), 1181-1191.

(28) Gao, P.; Chen, Z.; Gong, Y.; Zhang, R.; Liu, H.; Tang, P.; Chen, X.; Passerini, S.; Liu, J. The Role of Cation Vacancies in Electrode Materials for Enhanced Electrochemical Energy Storage: Synthesis, Advanced Characterization, and Fundamentals. Advanced Energy Materials 2020, 10 (14), 1903780.

(29) Keen, D. A. A Comparison of Various Commonly Used Correlation Functions for Describing Total Scattering. J Appl Cryst, J Appl Crystallogr 2001, 34 (2), 172-177.

(30) Christiansen, T. L.; Cooper, S. R.; Jensen, K. M. Ø. There's No Place like Real-Space: Elucidating Size-Dependent Atomic Structure of Nanomaterials Using Pair Distribution Function Analysis. Nanoscale Adv. 2020, 2 (6), 2234-2254.

(31) Jensen, K. M. Ø.; Andersen, H. L.; Tyrsted, C.; Bøjesen, E. D.; Dippel, A.-C.; Lock, N.; Billinge, S. J. L.; Iversen, B. B.; Christensen, M. Mechanisms for Iron Oxide Formation 
under Hydrothermal Conditions: An in Situ Total Scattering Study. ACS Nano 2014, 8 (10), 10704-10714.

(32) Cornell, R. M.; Schwertmann, U. The Iron Oxides, 2nd Editio.; Wiley VCH: Weinheim, 2003; p 705.

(33) Stievano, L.; Wagner, F. E. Mössbauer Spectroscopy. In Characterization of Solid Materials and Heterogeneous Catalysts; Che, M., Védrine, J. C., Eds.; Wiley-VCH Verlag GmbH \& Co. KGaA: Weinheim, Germany, 2012; pp 407-452.

(34) Brookes, C.; Wells, P. P.; Cibin, G.; Dimitratos, N.; Jones, W.; Morgan, D. J.; Bowker, M. Molybdenum Oxide on $\mathrm{Fe}_{2} \mathrm{O}_{3}$ Core-Shell Catalysts: Probing the Nature of the Structural Motifs Responsible for Methanol Oxidation Catalysis. ACS Catal. 2014, 4 (1), 243-250.

(35) Gaur, A.; Stehle, M.; Raun, K. V.; Thrane, J.; Jensen, A. D.; Grunwaldt, J.-D.; Høj, M. Structural Dynamics of an Iron Molybdate Catalyst under Redox Cycling Conditions Studied with in Situ Multi Edge XAS and XRD. Phys. Chem. Chem. Phys. 2020, 22 (20), 11713-11723.

(36) Brown, I. D. What Factors Determine Cation Coordination Numbers? Acta Crystallographica Section B Structural Science 1988, 44 (6), 545-553.

(37) Billinge, S. J. L. Viewpoint: The Nanostructure Problem. Physics 2010, 3.

(38) Goodwin, A. L. Opportunities and Challenges in Understanding Complex Functional Materials. Nature Communications 2019, 10 (1), 4461.

(39) Lappas, A.; Antonaropoulos, G.; Brintakis, K.; Vasilakaki, M.; Trohidou, K. N.; Iannotti, V.; Ausanio, G.; Kostopoulou, A.; Abeykoon, M.; Robinson, I. K.; Bozin, E. S. VacancyDriven Noncubic Local Structure and Magnetic Anisotropy Tailoring in $\mathrm{Fe}_{\mathrm{x}} \mathrm{O}-\mathrm{Fe}_{3-\delta} \mathrm{O}_{4}$ Nanocrystals. Phys. Rev. X 2019, 9 (4), 041044.

(40) Solano, E.; Frontera, C.; Puig, T.; Obradors, X.; Ricart, S.; Ros, J. Neutron and X-Ray Diffraction Study of Ferrite Nanocrystals Obtained by Microwave-Assisted Growth. A Structural Comparison with the Thermal Synthetic Route. J Appl Cryst 2014, 47 (1), 414420.

(41) Grau-Crespo, R.; Al-Baitai, A. Y.; Saadoune, I.; Leeuw, N. H. D. Vacancy Ordering and Electronic Structure of $\gamma-\mathrm{Fe}_{2} \mathrm{O}_{3}$ (Maghemite): A Theoretical Investigation. J. Phys.: Condens. Matter 2010, 22 (25), 255401.

(42) Rellán-Piñeiro, M.; López, N. One Oxygen Vacancy, Two Charge States: Characterization of Reduced $\alpha-\mathrm{MoO}_{3}(010)$ through Theoretical Methods. J. Phys. Chem. Lett. 2018, 9 (10), 2568-2573.

(43) Sun, W.; Dacek, S. T.; Ong, S. P.; Hautier, G.; Jain, A.; Richards, W. D.; Gamst, A. C.; Persson, K. A.; Ceder, G. The Thermodynamic Scale of Inorganic Crystalline Metastability. Science Advances 2016, 2 (11), e1600225.

(44) Grosse, G. PC-Mos II, Version 1.0 Manual and Program Documentation; 1993.

(45) Ravel, B.; Newville, M. ATHENA, ARTEMIS, HEPHAESTUS: Data Analysis for X-Ray Absorption Spectroscopy Using IFEFFIT. J. Synchrotron Rad. 2005, 12 (Pt 4), 537-541.

(46) Qiu, X.; Thompson, J. W.; Billinge, S. J. L. PDFgetX2: A GUI-Driven Program to Obtain the Pair Distribution Function from X-Ray Powder Diffraction Data. J. Appl. Cryst. 2004, 37 (4), 678-678.

(47) Farrow, C. L.; Juhas, P.; Liu, J. W.; Bryndin, D.; Božin, E. S.; Bloch, J.; Proffen, T.; Billinge, S. J. L. PDFfit2 and PDFgui: Computer Programs for Studying Nanostructure in Crystals. J. Phys.: Condens. Matter 2007, 19 (33), 335219. 
(48) Kresse, G.; Hafner, J. Ab Initio Molecular Dynamics for Liquid Metals. Phys. Rev. B 1993, $47(1), 558-561$.

(49) Kresse, G.; Hafner, J. Ab Initio Molecular-Dynamics Simulation of the Liquid-Metal-Amorphous-Semiconductor Transition in Germanium. Phys. Rev. B 1994, 49 (20), 1425114269.

(50) Kresse, G.; Furthmüller, J. Efficient Iterative Schemes for Ab Initio Total-Energy Calculations Using a Plane-Wave Basis Set. Phys. Rev. B 1996, 54 (16), 11169-11186.

(51) Pulay, P. Ab Initio Calculation of Force Constants and Equilibrium Geometries in Polyatomic Molecules. Molecular Physics 1969, 17 (2), 197-204.

(52) Blöchl, P. E. Projector Augmented-Wave Method. Phys. Rev. B 1994, 50 (24), 1795317979. https://doi.org/10.1103/PhysRevB.50.17953.

(53) Kresse, G.; Joubert, D. From Ultrasoft Pseudopotentials to the Projector Augmented-Wave Method. Phys. Rev. B 1999, 59 (3), 1758-1775.

(54) Perdew, J. P.; Ruzsinszky, A.; Csonka, G. I.; Vydrov, O. A.; Scuseria, G. E.; Constantin, L. A.; Zhou, X.; Burke, K. Restoring the Density-Gradient Expansion for Exchange in Solids and Surfaces. Phys. Rev. Lett. 2008, 100 (13), 136406.

(55) Dudarev, S. L.; Botton, G. A.; Savrasov, S. Y.; Humphreys, C. J.; Sutton, A. P. ElectronEnergy-Loss Spectra and the Structural Stability of Nickel Oxide: An LSDA+U Study. Phys. Rev. B 1998, 57 (3), 1505-1509.

(56) Wang, L.; Maxisch, T.; Ceder, G. Oxidation Energies of Transition Metal Oxides within the GGA+U Framework. Phys. Rev. B 2006, 73 (19), 195107.

(57) Dronskowski, R. The Little Maghemite Story: A Classic Functional Material. Advanced Functional Materials 2001, 11 (1), 27-29.

(58) Zhang, S. B.; Northrup, J. E. Chemical Potential Dependence of Defect Formation Energies in GaAs: Application to Ga Self-Diffusion. Phys. Rev. Lett. 1991, 67 (17), 2339-2342.

(59) Freysoldt, C.; Grabowski, B.; Hickel, T.; Neugebauer, J.; Kresse, G.; Janotti, A.; Van de Walle, C. G. First-Principles Calculations for Point Defects in Solids. Rev. Mod. Phys. 2014, 86 (1), 253-305.

(60) Lany, S.; Zunger, A. Assessment of Correction Methods for the Band-Gap Problem and for Finite-Size Effects in Supercell Defect Calculations: Case Studies for ZnO and GaAs. Phys. Rev. B 2008, 78 (23), 235104.

(61) Squires, A. G., Morgan B. J, DFT dataset for "The Impact of Solution Chemistry on Growth and Structural Features of Mo-substituted Spinel Iron Oxides". University of Bath Research Data Archive. https://researchdata.bath.ac.uk/id/eprint/993

(62) Van der Walt, S.; Colbert, S. C.; Varoquaux, G. The NumPy Array: A Structure for Efficient Numerical Computation. Computing in Science Engineering 2011, 13 (2), 22-30.

(63) Ong, S. P.; Richards, W. D.; Jain, A.; Hautier, G.; Kocher, M.; Cholia, S.; Gunter, D.; Chevrier, V. L.; Persson, K. A.; Ceder, G. Python Materials Genomics (Pymatgen): A Robust, Open-Source Python Library for Materials Analysis. Prof. Ceder 2012.

(64) Hunter, J. D. Matplotlib: A 2D Graphics Environment. Computing in Science Engineering 2007, 9 (3), 90-95.

(65) Virtanen, P.; Gommers, R.; Oliphant, T. E.; Haberland, M.; Reddy, T.; Cournapeau, D.; Burovski, E.; Peterson, P.; Weckesser, W.; Bright, J.; van der Walt, S. J.; Brett, M.; Wilson, J.; Millman, K. J.; Mayorov, N.; Nelson, A. R. J.; Jones, E.; Kern, R.; Larson, E.; Carey, C. J.; Polat, İ.; Feng, Y.; Moore, E. W.; VanderPlas, J.; Laxalde, D.; Perktold, J.; Cimrman, R.; Henriksen, I.; Quintero, E. A.; Harris, C. R.; Archibald, A. M.; Ribeiro, A. H.; Pedregosa, 
F.; van Mulbregt, P. SciPy 1.0: Fundamental Algorithms for Scientific Computing in Python. Nature Methods 2020, 17 (3), 261-272.

(66) Morgan, B. J. vasppy: A Python suite for manipulating VASP input and output. https://github.com/bjmorgan/vasppy (accessed April 26, 20201)

(67) Buckeridge, J. Equilibrium Point Defect and Charge Carrier Concentrations in a Material Determined through Calculation of the Self-Consistent Fermi Energy. Computer Physics Communications 2019, 244, 329-342.

(68) Morgan, B. J. py-sc-fermi. https://github.com/bjmorgan/py-sc-fermi (accessed April 26, 20201) 


\section{TOC GRAPHICS}
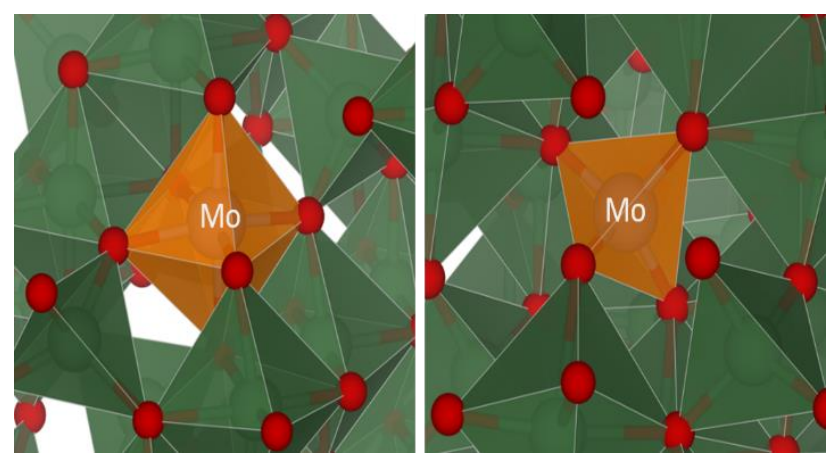

\section{Synopsis}

The growth and structural features of Mo-substituted iron nanoparticles were correlated to the chemistry of the crystallizing solution highlighting the role of Mo ions coordination mode on the stabilization of nanosized particles. 


\section{Supplementary Information}

\section{The Impact of Solution Chemistry on Growth and Structural Features of Mo-substituted Spinel Iron Oxides}

Chérazade Haouari ${ }^{\mathrm{a}, \mathrm{b}, \mathrm{c}}$, Alexander G. Squires ${ }^{\mathrm{d}, \mathrm{e}}$, Romain Berthelot ${ }^{\mathrm{a}, \mathrm{c}^{*}}$, Lorenzo Stievano ${ }^{\mathrm{a}, \mathrm{c}^{*}}$, Moulay Tahar Sougrati $^{\mathrm{a}, \mathrm{c}}$, Benjamin J. Morgan ${ }^{\mathrm{d}, \mathrm{e}}$, Oleg I.Lebedev ${ }^{\mathrm{f}}$, Antonella Iadecola ${ }^{\mathrm{c}}$, Olaf J. Borkiewicz ${ }^{\mathrm{g}}$, Damien Dambournet ${ }^{\mathrm{b}, \mathrm{c}^{*}}$

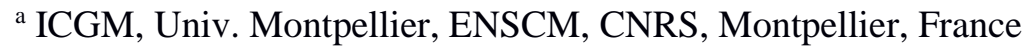

${ }^{\mathrm{b}}$ Sorbonne Université, CNRS, Physico-chimie des électrolytes et nano-systèmes interfaciaux, PHENIX, F-75005 Paris, France

${ }^{\mathrm{c}}$ Réseau sur le Stockage Electrochimique de l'Energie (RS2E), CNRS, Amiens, France

${ }^{\mathrm{d}}$ Department of Chemistry, University of Bath, BA2 7AY Bath, United Kingdom

e The Faraday Institution, Quad One, Harwell Science and Innovation Campus, Didcot OX11 ORA, U.K

${ }^{\mathrm{f}}$ Laboratoire CRISMAT, ENSICAEN, Université de Caen, CNRS, F-14050, Caen, France

${ }^{\mathrm{g}}$ X-ray Science Division, Advanced Photon Source, Argonne National Laboratory, 9700 South Cass Avenue, Argonne, Illinois 60439, United States 

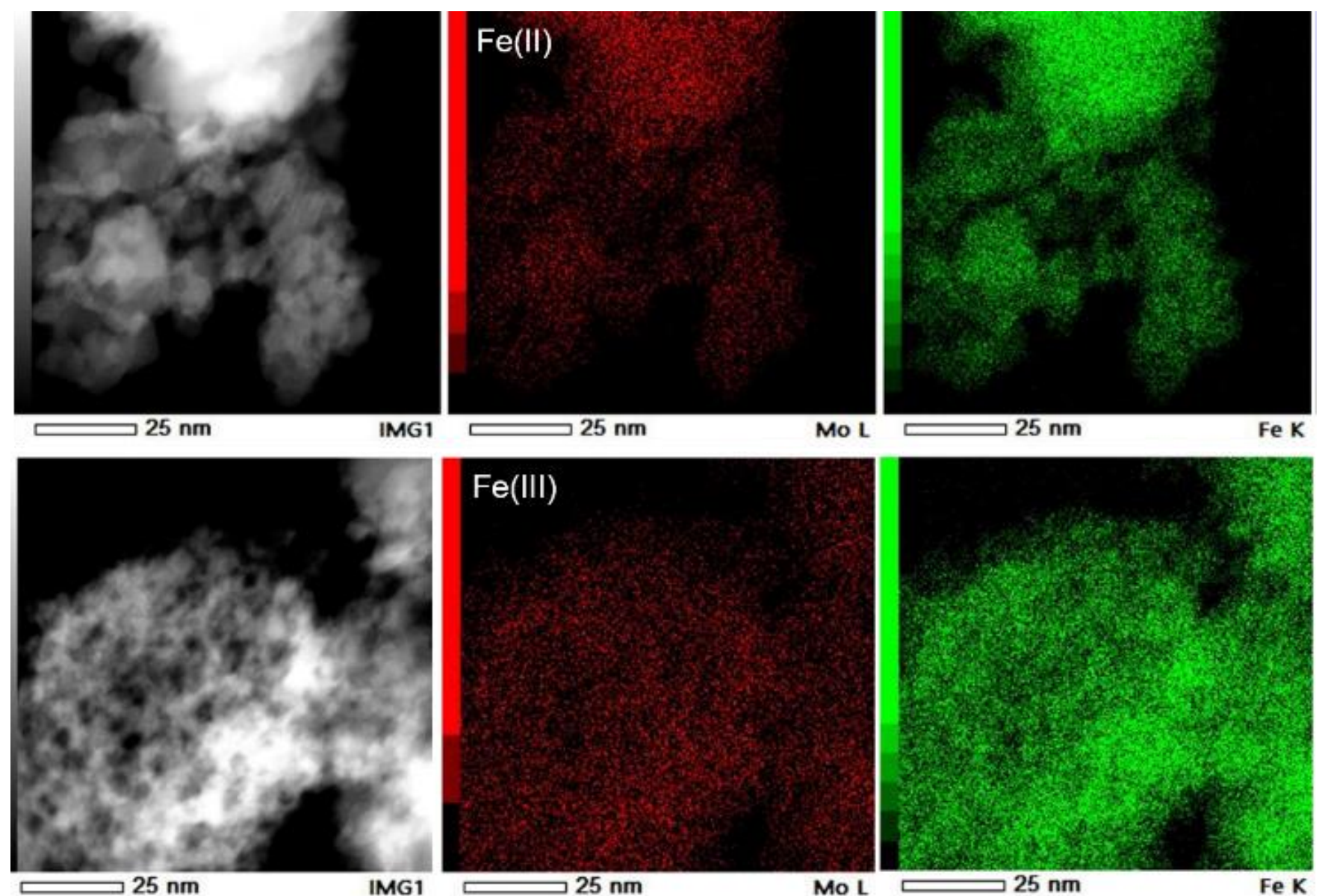

Figure S1. HAADF-STEM images of an isolated particle and corresponding EDX elemental mapping for Mo Land $\mathrm{Fe} \mathrm{K}$ on the samples prepared with $\mathrm{Fe}(\mathrm{II})$ and $\mathrm{Fe}(\mathrm{III})$ precursors.

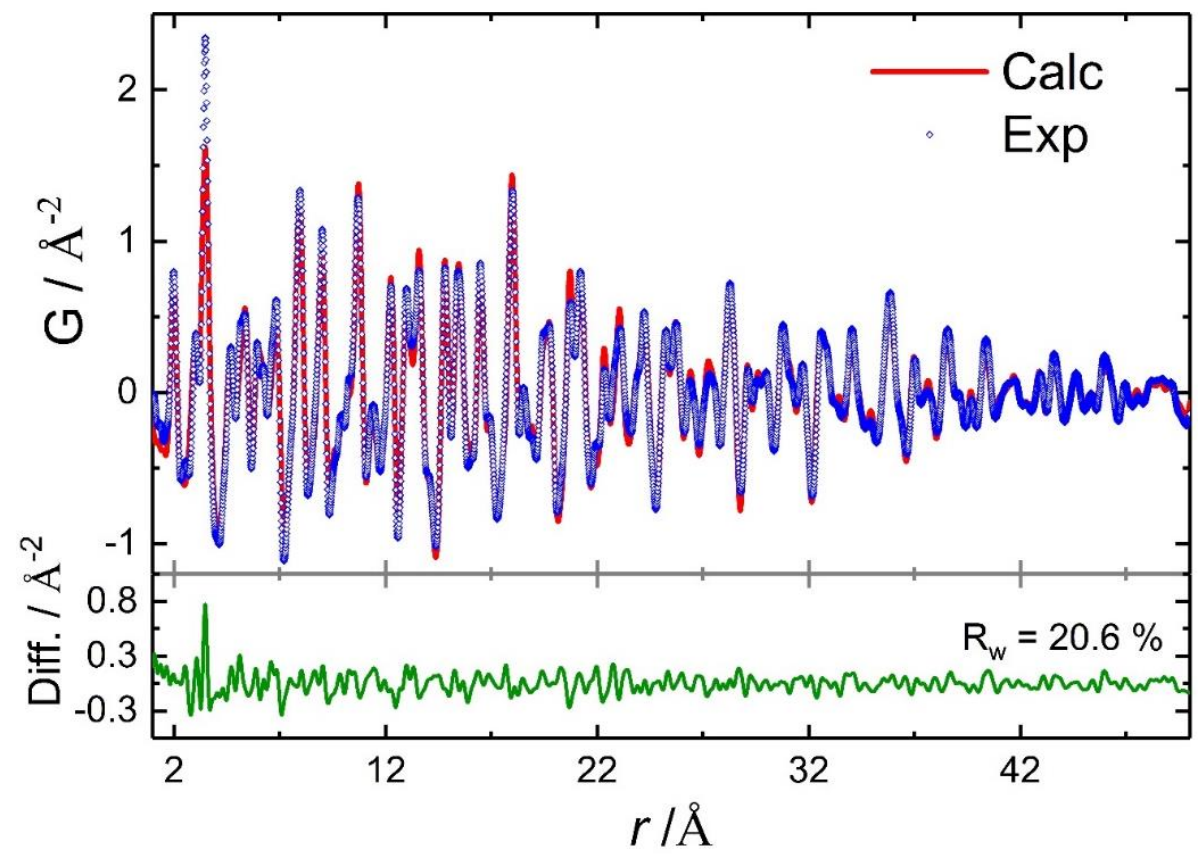

Figure S2. Refinement of the PDF data of the sample prepared with Fe(II) using a two-phase model based on $F d$ $3 m$ and $P 4_{3} 32$ space groups. 

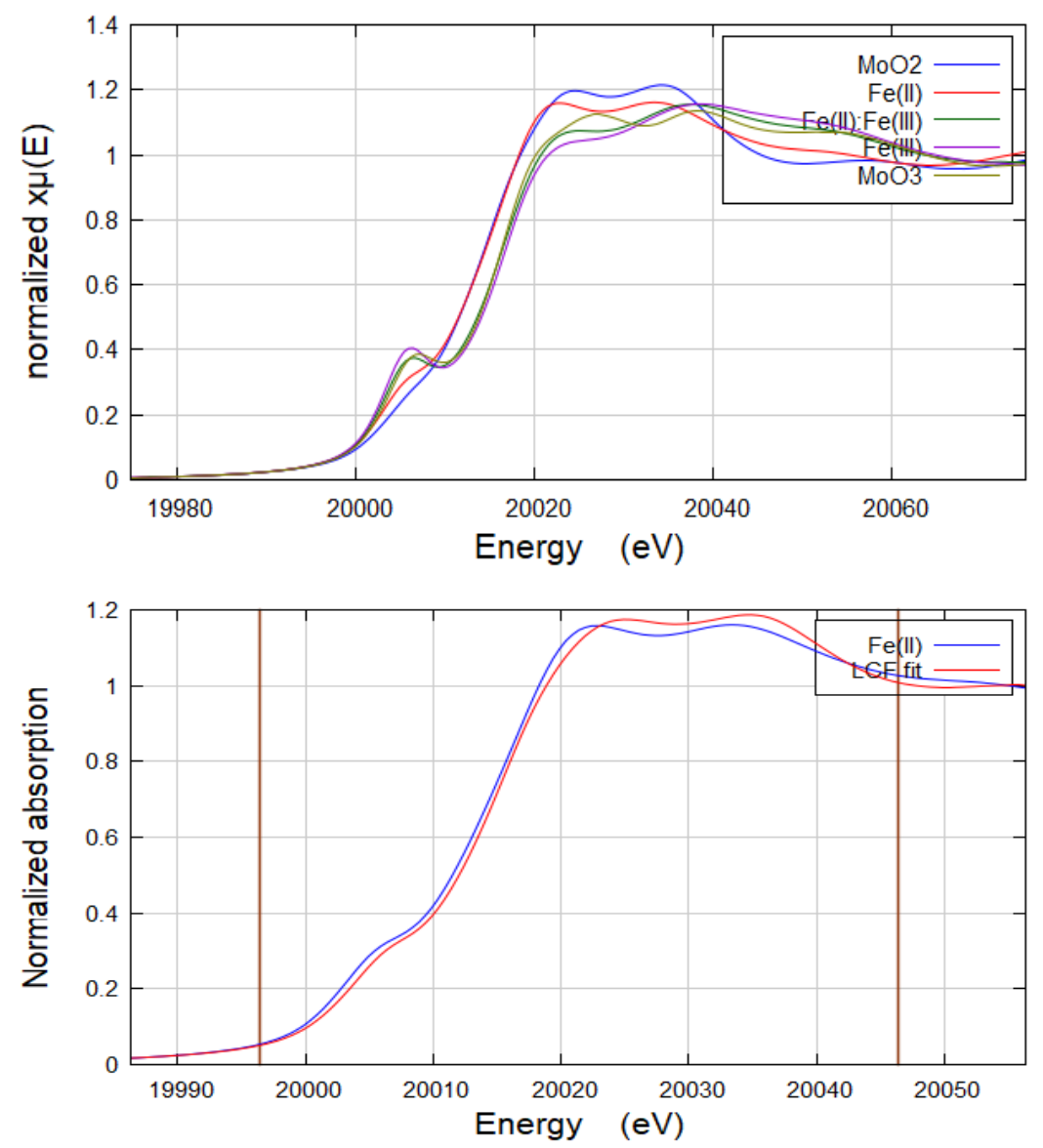

Figure S3. Top: comparison of the XANES signatures of the three samples obtained with different Fe precursors with the experimental spectra of $\mathrm{MoO}_{2}$ and $\mathrm{MoO}_{3}$ references. Bottom: linear combination fit of the XANES spectrum of the sample obtained starting from Fe(II) carried out using the spectra of $\mathrm{MoO}_{2}$ and $\mathrm{MoO}_{3}$ as references for $\mathrm{Mo}(\mathrm{IV})$ and $\mathrm{Mo}(\mathrm{VI})$, respectively, which provides a $\mathrm{Mo}(\mathrm{IV}) / \mathrm{Mo}(\mathrm{VI})$ ratio of content of about 3.

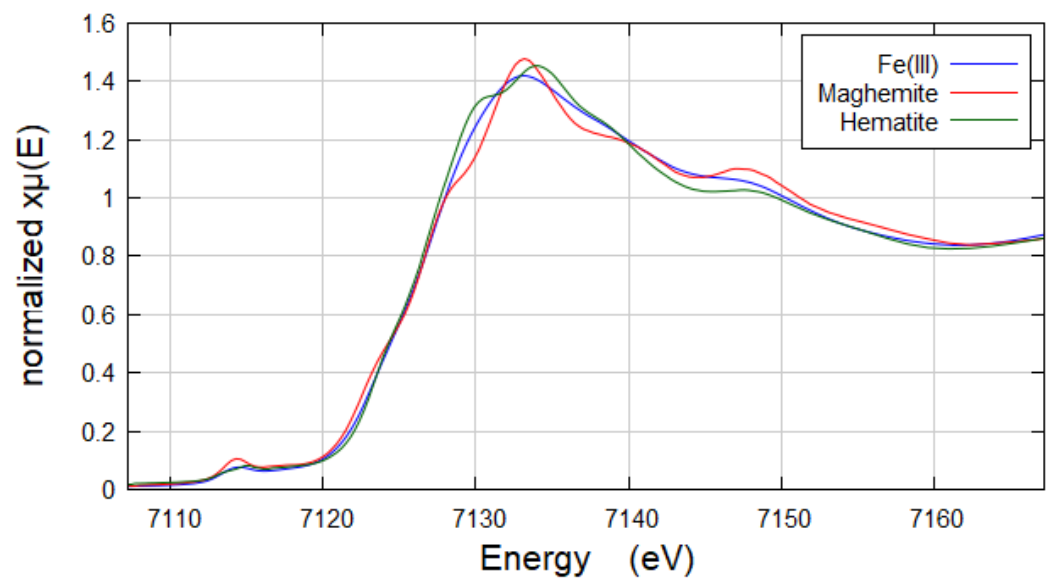

Figure S4. Comparison of the XANES signatures of the sample obtained with the Fe(III) precursor with the experimental spectra of hematite and maghemite references. 
The two series of spectra were fitted in the $\mathrm{R}$ space in the range 1.0-3.5 $\AA$ using the following approach for both Mo and Fe K-edge spectra:

- The first shell, between 1 and $2 \AA$, was divided in two contributions. The first contributions, including 4 oxygen neighbors, was set at a distance of about $1.8 \AA$, whereas the second one, including 6 oxygen neighbors, was set at a distance of $2.0 \AA$. The sum of the relative intensities of the two contributions was set equal to the value of the amplitude factor $\mathrm{S}_{0}{ }^{2}$, which was previously determined to be 0.8 and 0.75 for the Mo and Fe K-edge spectra by fitting the experimental spectrum of a reference material (crystalline $\mathrm{MoO}_{3}$ and $\alpha-\mathrm{Fe}_{2} \mathrm{O}_{3}$, respectively) measured in the same conditions. The $\sigma^{2}$ Debye-Waller factor was fitted to an identical value for both contributions.

- The second shell, between 2 and $3.5 \AA$ was fitted in a simplified manner considering only the contributions of two $\mathrm{Fe}$ neighbors at different distances. Considering that, in the theoretical spectrum of spinels, octahedral iron centers are surrounded by $6 \mathrm{Fe}$ neighbors at about $3 \AA$ and 6 more at $3.45 \AA$, whereas tetrahedral iron centers are only surrounded by 12 neighbors at $3.45 \AA$, the relative intensity of the first contribution was set equal to that of octahedral $\mathrm{Fe}-\mathrm{O}_{4}$ sites, and that of the second contribution to the weighted average between the intensities of octahedral and tetrahedral first-shell $\mathrm{Fe}-\mathrm{O}_{\mathrm{n}}$ sites. The $\sigma^{2}$ Debye-Waller factor was fitted to an identical value for both contributions.

The results of the fittings are shown in Figure S5 and S6, and the corresponding fitting parameters reported in Tables S1 and S2 for the Mo and Fe K-edges, respectively. 


\begin{tabular}{|c|c|c|c|c|c|}
\hline $\begin{array}{c}\text { Sample } \\
\text { precursors }\end{array}$ & Site & $\mathbf{S}_{0}^{2}$ & $\%$ & $\mathbf{R} / \AA$ & $\sigma^{2}$ \\
\hline \multirow{4}{*}{$\mathbf{F e}(\mathrm{II})$} & $\mathrm{Mo}_{4} \mathrm{O}_{4}$ & $0.31(4)$ & $39(5)$ & $1.72(3)$ & \multirow{2}{*}{$0.003(2)$} \\
\hline & $\mathrm{Mo}_{6} \mathrm{O}_{6}$ & $0.49(4)$ & $61(5)$ & $1.99(3)$ & \\
\hline & Mo-Fe 6 & $0.49(4)$ & - & $3.14(4)$ & \multirow{2}{*}{$0.006(2)$} \\
\hline & Mo-Fe 12 & $0.4(1)$ & - & $3.46(4)$ & \\
\hline \multirow{4}{*}{ Fe(II):Fe(III) } & $\mathrm{Mo}_{-} \mathrm{O}_{4}$ & $0.68(6)$ & $85(8)$ & $1.74(4)$ & \multirow{2}{*}{$0.005(3)$} \\
\hline & $\mathrm{Mo}_{-} \mathrm{O}_{6}$ & $0.12(6)$ & $15(8)$ & $2.03(4)$ & \\
\hline & $\mathrm{Mo}^{-\mathrm{Fe}_{6}}$ & $0.12(6)$ & - & $3.17(7)$ & \multirow{2}{*}{$0.006(5)$} \\
\hline & $\mathrm{Mo}-\mathrm{Fe}_{12}$ & $0.07(5)$ & - & $3.51(7)$ & \\
\hline \multirow{4}{*}{$\mathrm{Fe}(\mathrm{III})$} & $\mathrm{Mo}_{4} \mathrm{O}_{4}$ & $0.77(2)$ & $95(3)$ & $1.75(1)$ & \multirow{2}{*}{$0.005(3)$} \\
\hline & $\mathrm{Mo}_{-} \mathrm{O}_{6}$ & $0.03(2)$ & $5(3)$ & $2.05(3)$ & \\
\hline & Mo-Fe 6 & $0.03(2)$ & - & $2.82(5)$ & \multirow{2}{*}{$0.006(5)$} \\
\hline & Mo-Fe ${ }_{12}$ & $0.02(2)$ & - & $3.3(1)$ & \\
\hline
\end{tabular}

Table S1. Fitting parameters obtained by refining the Mo K-edge EXAFS spectra of the samples prepared using different iron precursors. 

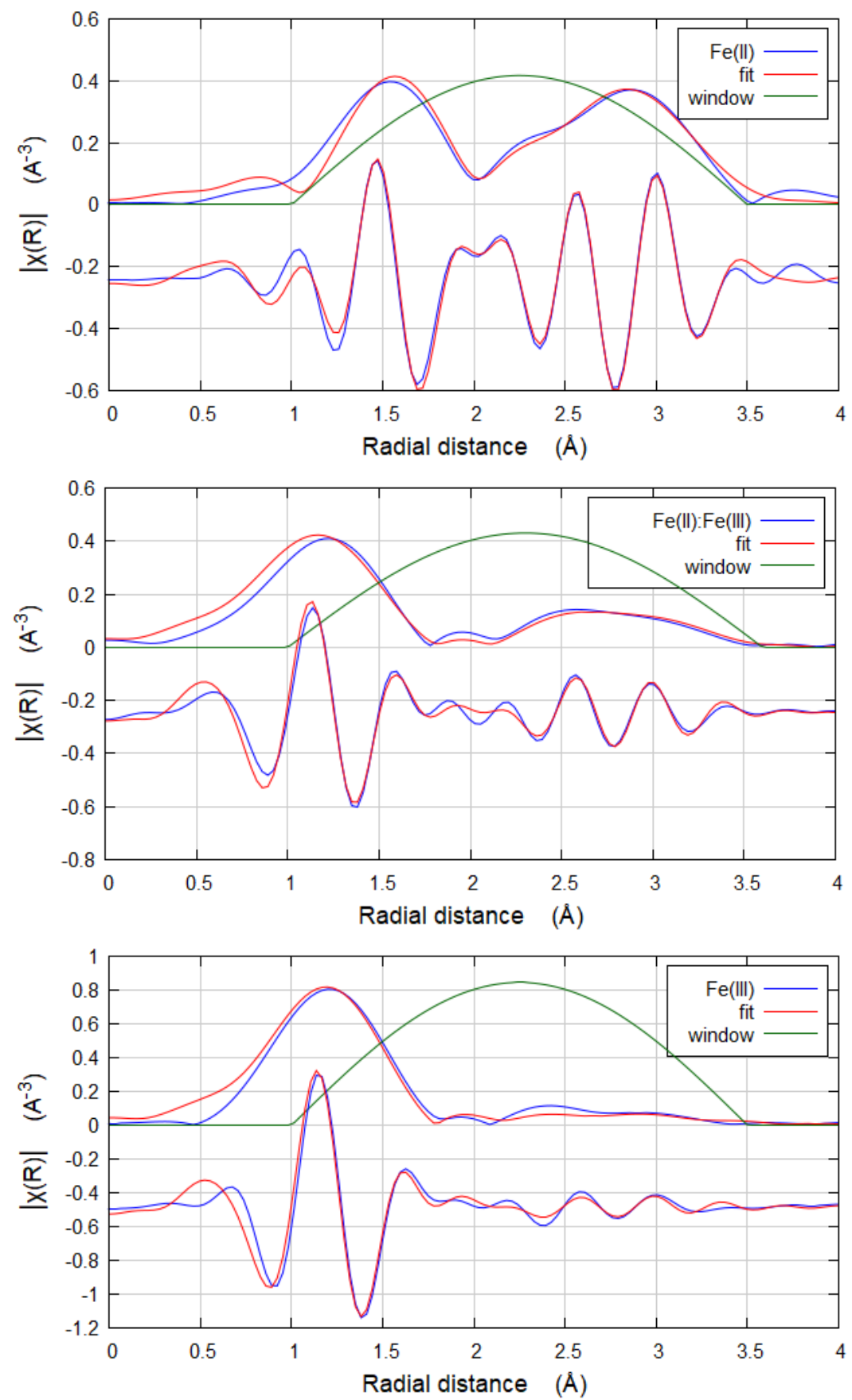

Figure S5. Fits of the Mo K-edge EXAFS spectra of the samples prepared using different iron precursors (left). 


\begin{tabular}{|c|c|c|c|c|c|}
\hline $\begin{array}{c}\text { Sample } \\
\text { precursors }\end{array}$ & Site & $\mathbf{S}_{0}^{2}$ & $\%$ & $\mathbf{R} / \AA$ & $\sigma^{2}$ \\
\hline \multirow{4}{*}{$\mathrm{Fe}(\mathrm{II})$} & $\mathrm{Fe}-\mathrm{O}_{4}$ & $0.37(7)$ & 49(9) & $1.89(2)$ & \multirow{2}{*}{$0.008(2)$} \\
\hline & $\mathrm{Fe}-\mathrm{O}_{6}$ & $0.38(7)$ & $51(9)$ & $1.99(2)$ & \\
\hline & $\mathrm{Fe}-\mathrm{Fe}_{6}$ & $0.38(8)$ & - & $2.98(2)$ & \multirow{2}{*}{$0.012(3)$} \\
\hline & $\mathrm{Fe}-\mathrm{Fe}_{12}$ & $0.56(8)$ & - & $3.44(2)$ & \\
\hline \multirow{4}{*}{$\mathrm{Fe}(I I): F e(I I I)$} & $\mathrm{Fe}-\mathrm{O}_{4}$ & $0.33(6)$ & $44(8)$ & $1.89(3)$ & \multirow{2}{*}{$0.007(2)$} \\
\hline & $\mathrm{Fe}-\mathrm{O}_{6}$ & $0.42(6)$ & $56(8)$ & $1.97(2)$ & \\
\hline & $\mathrm{Fe}-\mathrm{Fe}_{6}$ & $0.42(6)$ & - & $2.99(2)$ & \multirow{2}{*}{$0.015(3)$} \\
\hline & $\mathrm{Fe}-\mathrm{Fe}_{12}$ & $0.53(6)$ & - & $3.41(3)$ & \\
\hline \multirow{4}{*}{$\mathrm{Fe}(\mathrm{III})$} & $\mathrm{Fe}-\mathrm{O}_{4}$ & $0.23(7)$ & $34(9)$ & $1.89(3)$ & \multirow{2}{*}{$0.008(2)$} \\
\hline & $\mathrm{Fe}-\mathrm{O}_{6}$ & $0.52(7)$ & $66(9)$ & $1.96(2)$ & \\
\hline & $\mathrm{Fe}-\mathrm{Fe}_{6}$ & $0.52(7)$ & - & $3.02(2)$ & \multirow{2}{*}{$0.018(3)$} \\
\hline & $\mathrm{Fe}-\mathrm{Fe}_{12}$ & $0.49(7)$ & - & $3.39(3)$ & \\
\hline
\end{tabular}

Table S2. Fitting parameters obtained by refining the Fe K-edge EXAFS spectra of the samples prepared using different iron precursors. 

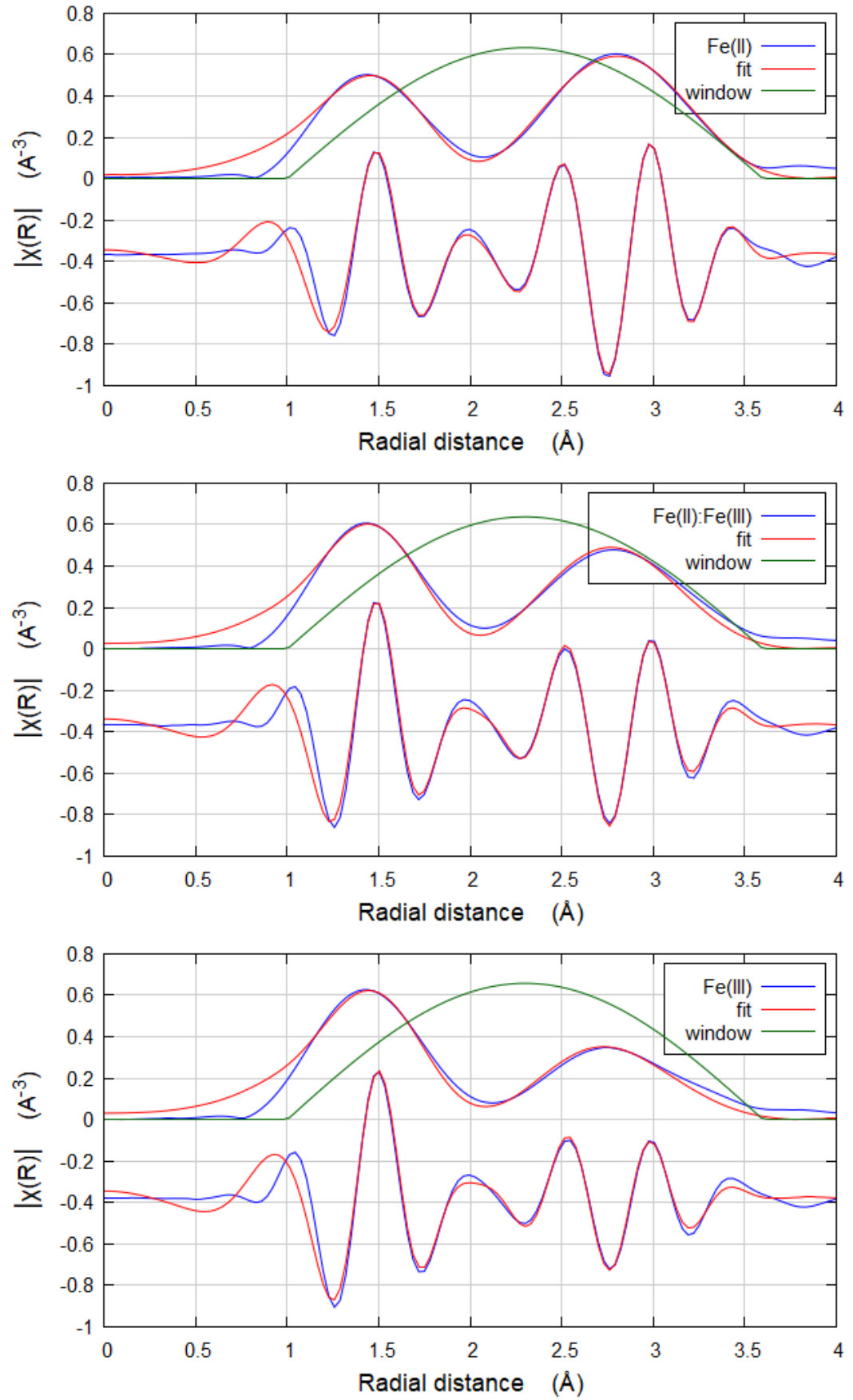

Figure S6. Fits of the Fe K-edge EXAFS spectra of the samples prepared using different iron precursors. 


\begin{tabular}{cccccc}
\hline $\begin{array}{c}\text { Sample } \\
\text { precursors }\end{array}$ & Site & $\mathbf{B}_{\text {hf }}(\mathbf{T})$ & $\Delta(\mathbf{m m} / \mathbf{s})$ & $\boldsymbol{\delta}(\mathbf{m m} / \mathbf{s})$ & Area $(\boldsymbol{\%})$ \\
\hline \multirow{2}{*}{$\mathbf{F e}(\mathbf{I I})$} & $\mathrm{Fe}(\mathrm{III})$ & - & $0.62(2)$ & $0.33(1)$ & $15(2)$ \\
& $\mathrm{Fe}^{2.5+}$ sextet & $40(1)$ & 0.00 & $0.88(2)$ & $20(2)$ \\
& $\mathrm{Fe}(\mathrm{III})$ distr. & $30-48$ & 0.00 & $0.35(2)$ & $65(3)$ \\
\hline $\mathbf{F e}(\mathbf{I I}): \mathbf{F e}(\mathbf{I I I})$ & $\mathrm{Fe}(\mathrm{III}) \mathrm{T}_{\mathrm{d}}$ & - & $0.48(5)$ & $0.25(1)$ & $16(2)$ \\
& $\mathrm{Fe}(\mathrm{III}) \mathrm{O}_{\mathrm{h}}$ & - & $0.65(4)$ & $0.33(2)$ & $15(3)$ \\
\hline $\mathbf{F e}(\mathbf{I I I})$ & $\mathrm{Fe}(\mathrm{III}) \mathrm{distr}$. & $30-48$ & 0.00 & $0.33(1)$ & $69(3)$ \\
\hline
\end{tabular}

Table S3. ${ }^{57} \mathrm{Fe}$ hyperfine parameters obtained by fitting the 57Fe Mössbauer spectra at room temperature of the samples prepared using different iron precursors.

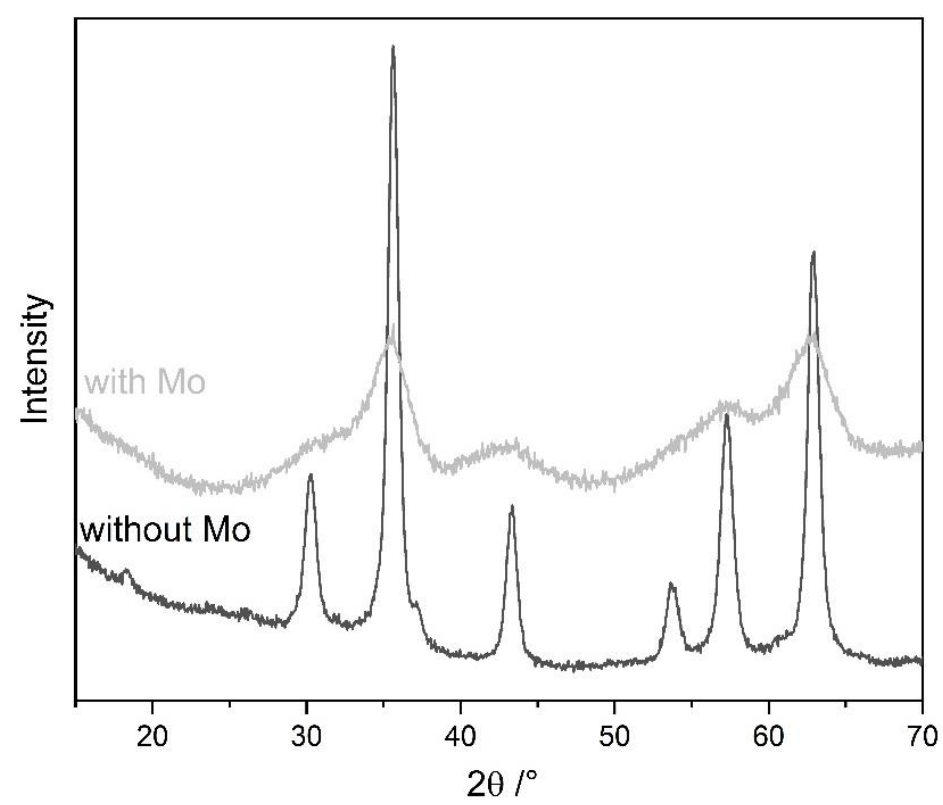

Figure S7. XRD patterns of the samples prepared with and without Mo. The samples were synthetized using an equimolar ratio of $\mathrm{Fe}(\mathrm{II})$ and $\mathrm{Fe}(\mathrm{III})$. 